\title{
Statistical Study on Cloud Top Heights of Cumulonimbi Thermodynamically Estimated from Objective Analysis Data during the Baiu Season
}

\author{
Teruyuki KATO, Syugo HAYASHI, and Masanori YOSHIZAKI ${ }^{1}$ \\ Meteorological Research Institute, Tsukuba, Japan \\ (Manuscript received 5 July 2006, in final form 9 April 2007)
}

\begin{abstract}
The level of neutral buoyancy (LNB) around the Japan Islands during the Baiu season in 2001-2005, estimated by lifting a low-level air with the maximum equivalent potential temperature in a vertical direction, is statistically examined from objective analysis data with the horizontal resolution of $20 \mathrm{~km}$, in order to clarify the surrounding atmospheric conditions under which cumulonimbi can form and develop. Three and two peaks are found in the vertical profiles of the appearance rate of the LNB over the sea and on the land, respectively. The high-level $(\sim 150 \mathrm{hPa})$ peak is very weak in June, and the low-level $(\sim 900 \mathrm{hPa})$ peak does not appear on the land. The other peak is found at the middle level $(\sim 700 \mathrm{hPa})$.

The theoretical study shows that the LNB during the Baiu season strongly depends on the lapse rate between the low and middle levels, when the variation of the low-level temperature is within a few degrees. This is because the LNB during the Baiu season rapidly becomes higher as the lapse rate increases. The statistical results show that the lapse rate around the Japan Islands strongly depends on convective activities over upstream regions, especially the southern part of China. Therefore, strong convective activities over the Baiu frontal zone in June produce the middle-level LNB around the Japan Islands to suppress the development of cumulonimbi. In July, the northward shift of the area with strong convective activities considerably releases such suppression, associated with that of the Baiu frontal zone.

The middle-level LNB also frequently appears over the other areas around the Baiu frontal zone, although it scarcely appears over the western part of the North Pacific Ocean. Therefore, the middle-level LNB that suggests the existence of cumulonimbi with a cloud top lower than several kilometers is one of the characteristic features around the Baiu frontal zone.
\end{abstract}

\section{Introduction}

Heavy rainfall is often observed around the Japan Islands during the Baiu season, especially in July. The Baiu season is the rainy period from early June thought late July around the Japan Islands. Most of the heavy rainfall

Corresponding author: Teruyuki Kato, Meteorological Research Institute, 1-1 Nagamine, Tsukuba, Ibaraki 305-0052, Japan.

E-mail: tkato@mri-jma.go.jp

(C) 2007, Meteorological Society of Japan

1 Present affiliation: Institute of observational Research for Global Change, Yokosuka, Japan events are caused by developed mesoscale convective systems (MCSs) with a band-shaped structure. Since such MCSs consist of cumulonimbi that form successively on their upstream side, the heavy rainfall strongly depends on the development of cumulonimbi.

The formation and maintenance mechanisms of heavy rainfall, observed around the Japan Islands during the Baiu season, have been investigated in case studies by using radar observations and numerical models. Such studies showed that the inflow of a humid air with high equivalent potential temperature into a 
(a)



Temperature $(T)$ (b)

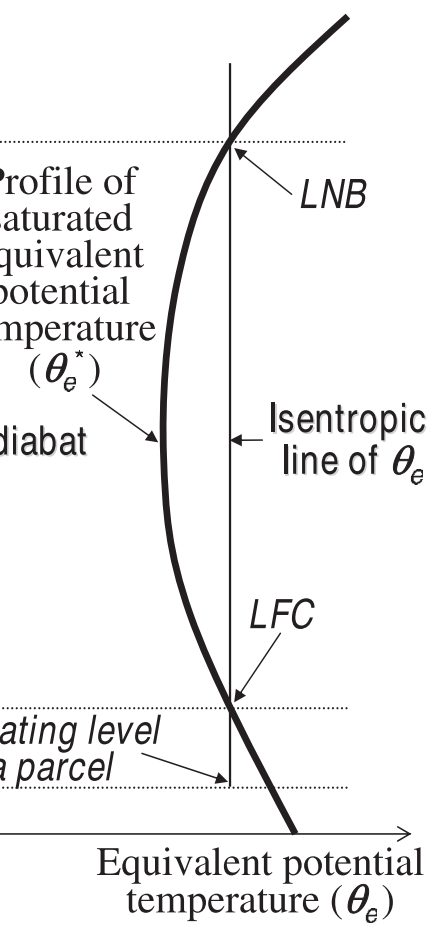

Fig. 1. Schematic diagram of significant levels for the formation and development of cumulonimbi, estimated with the thermodynamics. The lifting condensation level $(L C L)$, the level of free convection $(L F C)$, and the level of neutral buoyancy $(L N B)$ is estimated from the originating level of a parcel.

near-surface wind convergence area caused the successive formation of cumulonimbi to result into heavy rainfall (e.g., Kato 1998; Kato and Goda 2001).

The surrounding atmospheric conditions around the Japan Islands during the Baiu season, under which heavy rainfall is caused, have been also investigated statistically by using upper-air sounding data and objective analysis data (e.g., Matsumoto et al. 1971; Kato et al. 2003). Previous studies showed that a low-level humid air passing around the Pacific high pressure zone flows into the Baiu frontal zone. This low-level humid air often causes heavy rainfall around the Baiu frontal zone. However, its dependency on the development of cumulonimbi has never been examined statistically.

Cumulonimbi can form when a low-level humid air is lifted to the level of free convection (LFC) against the negative buoyancy under the latently unstable atmospheric condition, and then they can develop to the height where they lose their upward motion. This height roughly corresponds to the level of neutral buoyancy (LNB), whenever a dry air is not intruded into cumulonimbi and the convective available potential energy (CAPE) is small. The abovementioned processes are depicted in Fig. 1. In the case that the vertical profile of temperature $T$ (Fig. 1a) is used, a low-level humid air is lifted adiabatically from the originating level to the lifting condensation level (LCL) along the dry adiabat, and it is lifted further along the moist adiabat. The first point at which the moist adiabat crosses the profile of $T$ is the LFC, and the second one is the LNB. The LFC and LNB can also be estimated using the equivalent potential temperature $\theta_{e}$ of a lifted humid air and the vertical profile of the saturated potential temperature $\theta_{e}^{*}$ (Fig. 1b). The lower point at which in the vertical profile of the $\theta_{e}^{*}$ it is equal to the $\theta_{e}$ of a lifted humid air is the LFC, and the higher one is the LNB. This is because the $\theta_{e}$ conserves independently of the condensation of water vapor, and the $\theta_{e}^{*}$ is calculated only from $T$ and pressure (or height). 
The LNB can roughly determine the cloud top heights of cumulonimbi around the Baiu frontal zone, where the latently unstable atmospheric condition is usually so weak that the CAPE can become small. This is because the atmosphere over the Baiu frontal zone is humidified and warmed through convective activities. The LNB has been never examined statistically, and it has been used only in case studies. Here, it should be noted that the cloud top heights of cumulonimbi become higher than the LNB, because they can maintain their upward motions for a little time even above the LNB.

The primary purpose of this study is to statistically examine the LNB around the Japan Islands during the Baiu season by using objective analysis data, in order to clarify the surrounding atmospheric conditions under which cumulonimbi can form and develop. Moreover, the characteristic features around the Baiu frontal zone are examined from the vertical profile of the appearance rate of the LNB.

The contents of this paper are organized in the following manner. The statistical method, and areas to calculate the LNB, are shown in Section 2. The statistical results for the appearance heights of the LNB around the Japan Islands are shown in Section 3. The factors to determine their heights are examined from environmental fields, such as the maximum equivalent potential temperature and the lapse rate. The influence of the inflow of a middlelevel dry air is also examined. In Section 4, the statistical results for the other areas around the Baiu frontal zone are examined. Case studies on the relationship between heavy rainfall and the LNB during the Baiu season are described in Section 5. The summary and discussions are presented in the last section.

\section{Statistical method and areas}

In this study, two types of the regional analysis data (RANAL), produced operationally four times per day (03 JST, 09 JST, 15 JST, 21 JST, where JST $=$ UTC +9 hours) by the Japan Meteorological Agency (JMA), are used to examine the LNB. One type is coordinated with 20 pressure levels of $1000,950,925,900,850,800,700$, $600,500,400,300,250,200,150,100,70,50$, 30,20 , and $10 \mathrm{hPa}$. The other has $40 \sigma$-p hybrid vertical levels that consist of constant and variable parts of pressure ${ }^{2}$. The statistical period is two months consisting of June and July in 2001-2005.

The LNB at horizontal grid points of the RANAL with $\sigma$-p hybrid vertical levels, over which the atmospheric condition is latently unstable, is calculated by lifting an air with the maximum $\theta_{e}\left(\theta_{e \max }\right)$ below a level of $800 \mathrm{hPa}^{3}$. This LNB is the highest level to be estimated, because the LNB becomes higher with the increase of the $\theta_{e}$ of a lifted air (see Fig. 1b). In the case that the $\theta_{e}^{*}$ above the originating level of a lifted air is larger than the $\theta_{\text {emax }}$, i.e., the atmospheric condition is not latently unstable, the LNB is not calculated. It should be noted that the LNB at the grids where the relative humidity $\mathrm{RH}$ at levels of $700 \mathrm{hPa}$ and $500 \mathrm{hPa}$ is larger than $98 \%$ is excluded from the statistics in this study, because there have already existed convective activities. Moreover, the LNB at the grids where the distance between the LFC and the originating level of a lifted air is larger than $200 \mathrm{hPa}$ is also excluded, because a low-level air is necessary to be lifted against the negative buoyancy to the level at which cumulonimbi form.

For the calculation of the $\theta_{e}$, the water vapor pressure $e$ is correctly considered as

$$
\theta_{e}=T\left(\frac{p_{0}}{p-e_{L C L}}\right)^{R / C_{p}} \exp \left(\frac{L\left(T_{L C L}\right) q}{C_{p} T_{L C L}}\right)
$$

where $p_{0}$ is the standard pressure $(=1000 \mathrm{hPa}), R$ is the gas constant, $C_{p}$ is the specific heat at constant pressure, $L$ is the latent heat of vaporization, $q$ is the mixing ratio of water vapor of a lifted air, and the subscript ' $L C L$ ' denotes the value when a lifted air arrives at the LCL. In the case that the $e$ is approximately neglected from Eq. (1), the LNB is calculated lower than the correct one ${ }^{4}$, because

2 The variable part is given as a function of surface pressure, and the vertical resolution at the lowest level is about $5 \mathrm{hPa}$. The other information is described in JMA (2002).

3 In this study, the surrounding atmospheric conditions under which cumulonimbi form are examined by lifting a humid air from the lower level, but not for the moist convection that exists only at the middle and/or upper levels.

4 To calculate the $\theta_{e}$ more correctly, the formula of Bolton (1980) should be used because Eq. (1) is also an approximation. However, in this statistical study, such strict $\theta_{e}$ is not required. 


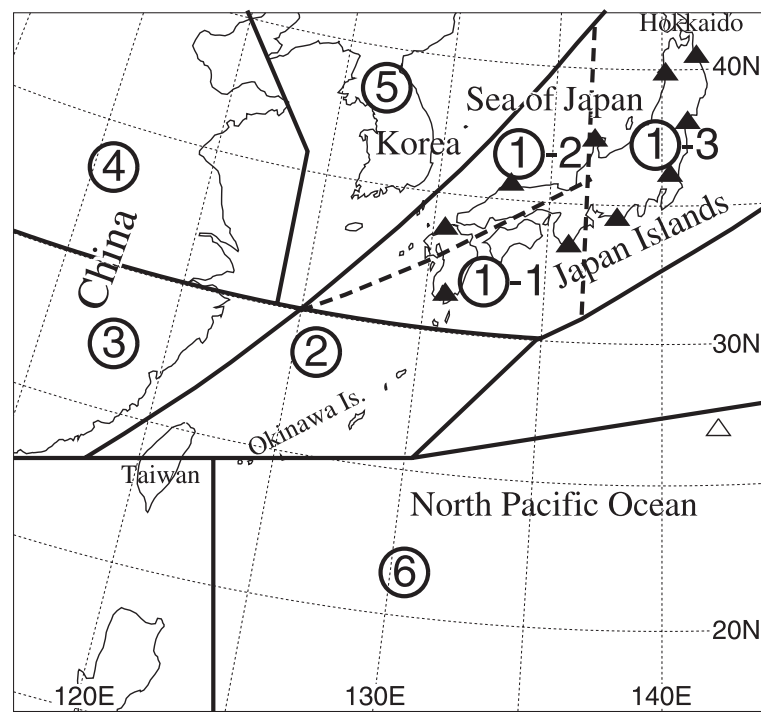

Fig. 2. Statistical areas. Black (white) triangles denote the locations of upperair sounding stations in the domain (1) (domain (6), used in this study.

the low-level $\theta_{e}$ is considerably underestimated, due to the exponentially increase of the $e$ with $T$. Further, by using the $\theta$, the CAPE can be estimated as

$$
C A P E=g \int_{L F C}^{L N B} \frac{\theta^{\prime}-\theta}{\theta} d z
$$

where $g$ is the gravity acceleration, and $\theta^{\prime}$ is the $\theta$ of a lifted air on the moist adiabat.

Figure 2 shows the statistical areas. The LNB over the area around the Japan Islands,

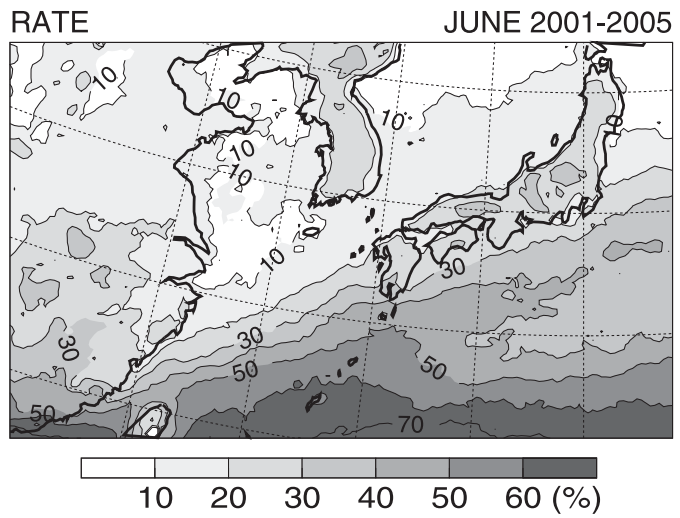

denoted by the domain (1) in Fig. 2, is examined mainly in this study. The area around the Okinawa Islands (domain (2) in Fig. 2) is excluded from the domain (1), because the Baiu season usually ends in late June there. Most of the area around Hokkaido Island, located north of the Japan Islands, is also excluded, because the Baiu season does not exist there. Therefore, it should be noted that the area of the Japan Islands denotes the domain (1) in this study. In order to examine regional features, the domain (1) is subdivided into three areas: the Pacific Ocean side (domain (1)-1), the Japan-Sea side (domain (1)-2) of western Japan, and eastern Japan (domain (1)-3).

For the other areas around the Baiu frontal zone: the Okinawa Islands (domain (2)), the southern part of China (domain (3), the northern part of China (domain (4)), and Korea (domain (5)), the LNB is also examined to clarify the common features to that around the Japan Islands. The characteristic features of the LNB over the western part of the North Pacific Ocean (domain (6) ) are examined to find differences from those around the Baiu frontal zone. These examinations are described in section 4 .

Figure 3 shows the appearance rate distributions of the LNB, calculated by the abovementioned method, around the Baiu frontal zone in June and July between 2001 and 2005. The distributions also mean the frequency with which the latently unstable atmospheric condition appears. The rates around the Japan Islands are $20-30 \%$ in June, and $20-40 \%$ in July. The rates over the western

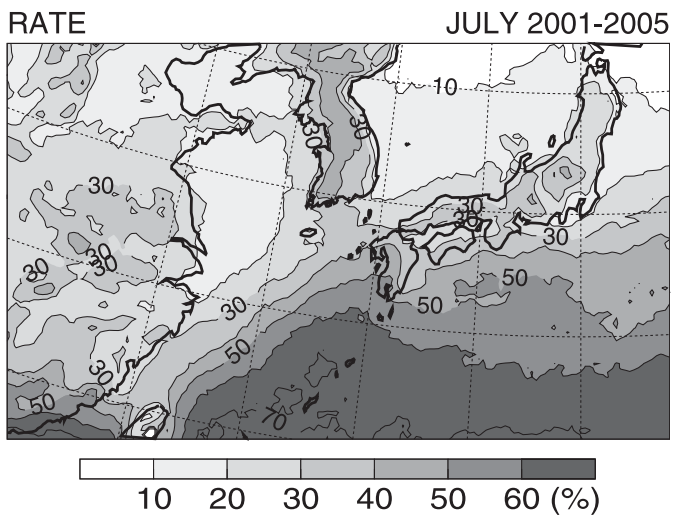

Fig. 3. Appearance rate distributions of the LNB, estimated by lifting an air with the maximum equivalent potential temperature in June (left panel) and July (right panel) between 2001 and 2005. Regional analysis data of the JMA is used in this estimation. 

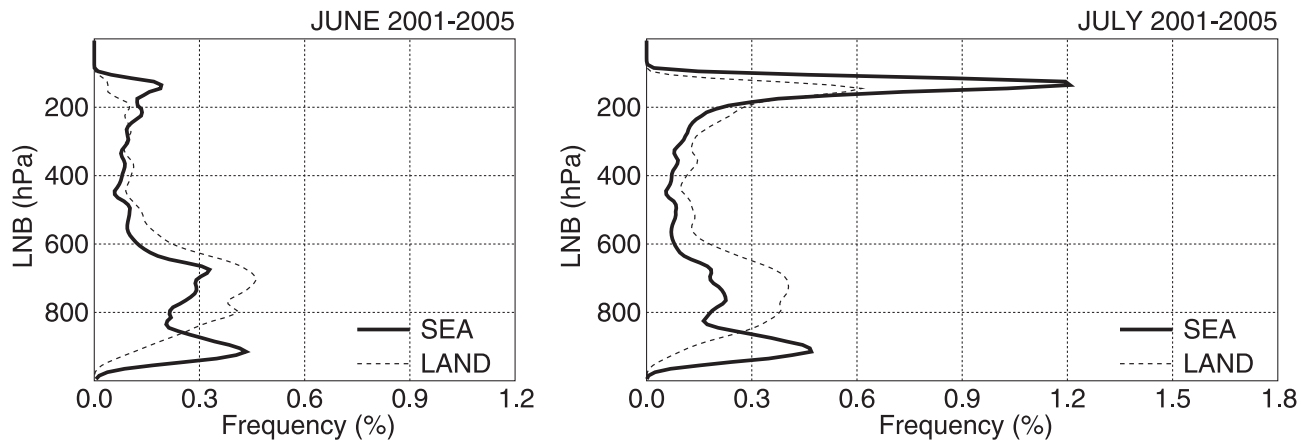

Fig. 4. Vertical profile of the appearance rate of the LNB over the sea (broken lines) and on the land (solid lines), estimated by lifting an air with the maximum equivalent potential temperature around the Japan Islands, domain (1) in Fig. 2, in June (left panel) and July (right panel) between 2001 and 2005. Regional analysis data of the JMA is used in this estimation. Solid and dashed lines denote the rates over the sea and on the land, respectively. Each rate is calculated by dividing the LNB into 100 vertical levels with an interval of $1 \mathrm{hPa}$.

part of the North Pacific Ocean are around 70\% in both June and July (not shown). For example accumulated appearance numbers of the LNB in domain (1)-2, between 2001 and 2005 are 58642 (20646) in June, and 92845 (27909) in July over the sea (on the land). These numbers are large enough to make statistical studies.

\section{Results around the Japan Islands}

\subsection{Vertical profile of the appearance rate of the $L N B$}

The vertical layers where the LNB appears with high frequency around the Japan Islands are examined at first. In the domain (1) in Fig. 2 , the vertical profiles of the appearance rate of the LNB in June and July, between 2001 and 2005, are shown in Fig. $4^{5}$. Each rate is calculated by dividing the LNB into 100 vertical levels, with an interval of $10 \mathrm{hPa}$. The peaks in the profiles of the appearance rate of the LNB can be classified into three vertical parts: the lower part around $900 \mathrm{hPa}$ (hereafter called $\mathrm{LP}$ ), the middle part around $700 \mathrm{hPa}(\mathrm{MP})$, and the upper part around $150 \mathrm{hPa}$ (UP).

In June the UP is very weak over the sea, and it does not appear on the land. This indicates that cumulonimbi developing to the tro-

5 In the product of the RANAL, the optimum interpolation method was replaced with the 4dimensional variational data-assimilation method on 19 June 2003. However, characteristic features found in statistical results hardly changes by this replacement (see Fig. 15). popause, such as the deep convection, are little around the Japan Islands in June. On the other hand, the UP becomes large in July, and consequently many cumulonimbi can develop to the deep convection that causes heavy rainfall. Since the appearance rate of the LNB suggests the possibility to generate cumulonimbi, it can be expected from the difference of the UP between June and July that weak rainfall is predominant during the first half of the Baiu season, and strong rainfall is frequently observed during the latter half.

In both June and July, the MP appears with higher frequency on the land than over the sea. This reason is examined in Subsection 3.5. Cumulonimbi that form under the surrounding atmospheric condition with middle-level LNB could correspond with the convection of medium depth (CMD) that was found in the statistical study with radar data, and defined by Zhang et al. (2006). The CMD is the concept for MCSs consisting of cumulonimbi whose echo top height with the radar reflectivity of $15 \mathrm{dBZ}$ is equal to less than $8 \mathrm{~km}$, and it often appears around the Meiyu front in China. For actual cases, cumulonimbi of which the CMD consists develop considerably higher than a level of about $700 \mathrm{hPa}$. This could be because they can maintain their upward motions even above the LNB against the negative buoyancy that is considerably smaller than around the tropopause. The maintenance of upward motions should be examined in future works. 
The LP appears only over the sea. The convection that forms under the surrounding atmospheric condition with low-level LNB corresponds with the shallow convection that is found in the convectively mixed layer over the sea. The convectively mixed layer usually develops to a height of $1-1.5 \mathrm{~km}$, and in the layer of the vertical profile of the $\theta_{e}$ it almost becomes moist isentropic. Under such condition, the lapse rate $\Gamma$ ( $\equiv-d T / d z$, where $z$ is the height) in the convectively mixed layer becomes close to the moist adiabatic lapse rate, and consequently the LNB becomes lower (see Appendix). On the other hand, the $\Gamma$ in the atmospheric boundary layer on the land becomes close to the dry adiabatic lapse rate, because the $\theta$ in the layer almost becomes isentropic. Under such condition, since the $\Gamma$ between the lower and middle levels increases, the LNB scarcely appears at the lower level (see Fig. A2).

Here the above-mentioned statistical features of the LNB on the land, estimated from the RANAL, are verified using upper-air sounding data around the Japan Islands. Figure 5 shows the vertical profiles of the appearance rate of the LNB, calculated with the same statistical method from observations at 09 JST and 21 JST, at the points shown by black triangles in Fig. 2 in June and July between 1989 and 2005. Observation data for 17 years are used to secure sample numbers. In comparison with the observations (Fig. 5), the appearance rates



Fig. 5. Same as Fig. 4, but for those estimated from upper-air sounding data in June (bold line) and July (thin line) between 1989 and 2005. The locations of upper-air sounding are shown by black triangles in Fig. 2. of the LNB in statistical results with the RANAL are underestimated by about $50 \%$, especially for the MP (Fig. 4). However, except for this underestimation, the statistical features of the LNB, found in the RANAL, are similar to those in the observations.

Next the regional features around the Japan Islands in the appearance rate of the LNB are examined. Figure 6 shows the vertical profiles of the appearance rate of the LNB in June and July between 2001 and 2005 for the Pacific Ocean side (domain (1)-1 in Fig. 2), and the Japan-Sea side (domain (1)-2) of western Japan, and eastern Japan (domain (1)-3). On the Pacific Ocean side (Fig. 6a), the UP remarkably appears even in June over the sea, and its appearance rate in July is considerably larger than those in the other areas (Figs. $6 \mathrm{~b}$ and $6 \mathrm{c}$ ). This indicates that the deep convection can form with higher frequency on the Pacific Ocean side. It is consistent with the fact that many heavy rainfall events are observed on the Pacific Ocean side during the Baiu season. On the other hand, the UP in July is relatively weak in the other areas, especially on the land in eastern Japan (broken line in right panel of Fig. 6c). This reason is examined in the next subsection. Here it should be noted that the MP over the sea on the Pacific Ocean side in July shifts to the lower level, and it becomes relatively weak. This feature is slightly different from those in June and in the other areas, and it is rather closer to that over the western part of the North Pacific Ocean (see Fig. 19).

\subsection{Environmental fields to determine the $L N B$}

As described in the introduction, the LNB can be easily estimated by the vertical level at which the $\theta_{e}$ of a lifted humid air is equal to the $\theta_{e}^{*}$ in the environmental field (see Fig. 1b). Therefore, statistical studies for vertical $\theta_{e}^{*}$ profiles and the $\theta_{e}$ of a lifted humid air enable us to easily examine the LNB. From this examination, however, the atmospheric condition can not be easily understood, because the $\theta_{e}^{*}$ is a function of $T$ and height. In this study, the averaged $\Gamma$ below several vertical levels is examined, instead of vertical $\theta_{e}^{*}$ profiles, and the factors to determine the LNB are discussed by converting the averaged $\Gamma$ to vertical $\theta_{e}^{*}$ profiles in the final section. 



Fig. 6. Same as Fig. 4, but for (a) the Pacific Ocean side, domain (1)-1 in Fig. 2, and (b) the Japan-Sea side, domain (1)-2, of western Japan, and (c) eastern Japan, domain (1-3.

The LNB can be calculated when the lowlevel $T$ and the $\theta_{e}$ of a lifted humid air are given under the atmospheric condition with a constant $\Gamma^{6}$ (see Fig. A2a). Moreover, as described in the Appendix, higher low-level $T$, higher $\theta_{e}$ of a lifted air, and/or a larger $\Gamma$ can make the LNB higher (see Fig. A2b). In this subsection, therefore, the low-level $T$ and the $\Gamma$ averaged between the lower and middle levels are examined to clarify the environmental

6 Although real atmosphere never has a constant $\Gamma$, the averaged $\Gamma$ between the lower and middle levels can be used to check whether the LNB is higher than the middle level or not. fields that determine the LNB, as well as the $\theta_{e}$ of a lifted air.

Figure 7 shows the averaged fields of the $T$ at a height of about $500 \mathrm{~m}\left(T_{500 \mathrm{~m}}\right)$, the $\theta_{e \max }$ and the averaged $\Gamma$ between about $500-\mathrm{m}$ altitude and a 500-hPa level in June and July between 2001 and 2005, depicted from the RANAL. The $T_{500 \mathrm{~m}}$ (Fig. 7a) becomes higher by about $3 \mathrm{~K}$ between June and July over the sea around the Japan Islands, due to the increase of the sea surface temperature (not shown). However this raise of low-level temperature can not explain the enhancement of the UP in July (see the Appendix). 
(a)

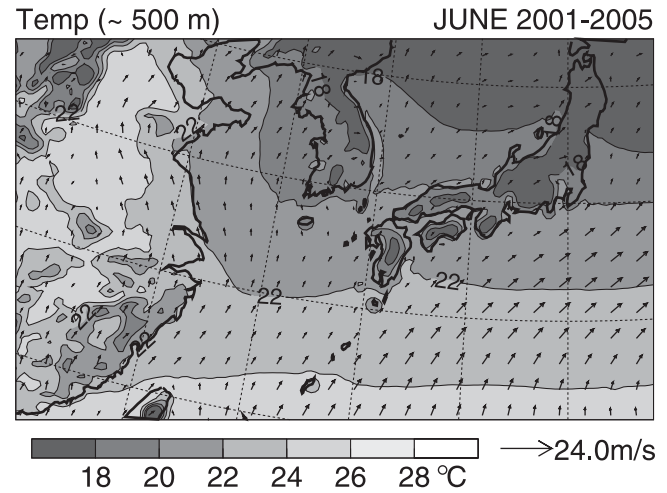

(b) $\theta_{\mathrm{e}} \max$

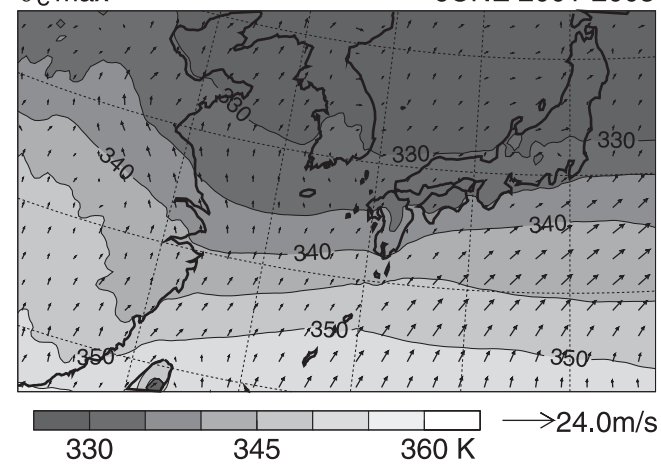

(c) $\Gamma(500 \mathrm{~m}-500 \mathrm{hPa})$

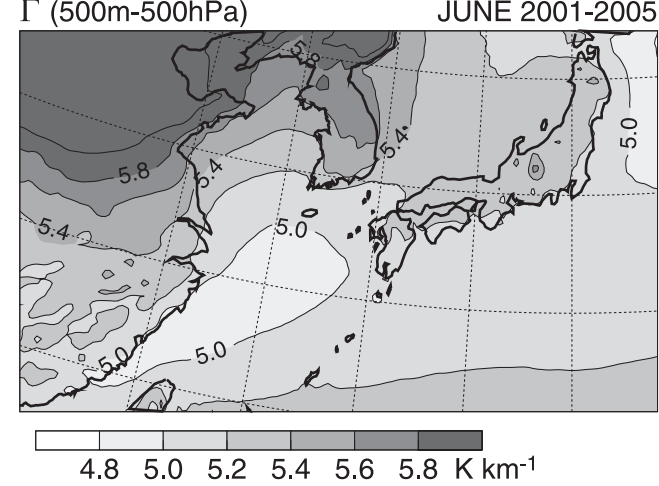

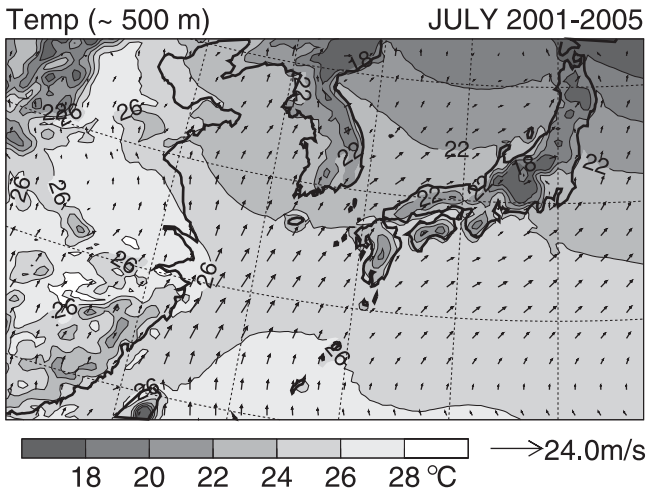
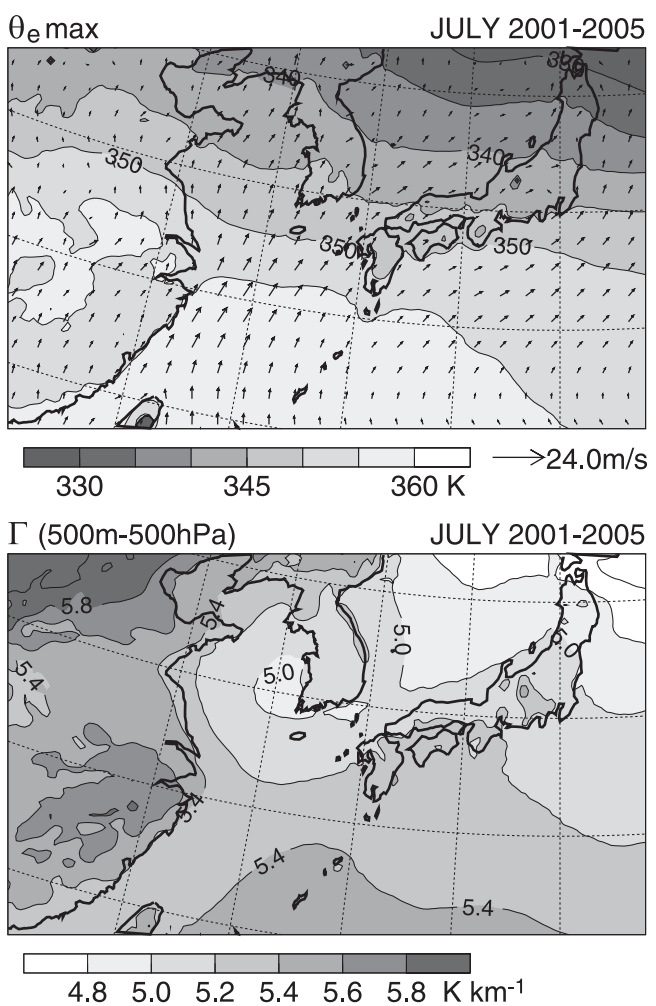

Fig. 7. Averaged field of (a) the temperature at a height of about $500 \mathrm{~m}$, (b) the maximum equivalent potential temperature and (c) the lapse rate between an about 500-m altitude and a 500-hPa level in June (left panels) and July (right panels) between 2001 and 2005, depicted from regional analysis data of the JMA. Vectors in (a) and (b) present the horizontal winds at a height of about $500 \mathrm{~m}$.

On the other hand, the increase of the $\theta_{\text {emax }}$ between June and July is remarkably found around the Japan Islands (Fig. 7b). This increase is caused by a low-level humid air that passes around the Pacific high pressure zone and flows into the Baiu frontal zone (see wind vectors in right panels of Fig. 7), and it is about $15 \mathrm{~K}$ in western Japan, and about $10 \mathrm{~K}$ in eastern Japan. Between June and July, the $\Gamma$
(Fig. 7c) increases by $0.2-0.3 \mathrm{~K} \mathrm{~km}^{-1}$ on the Pacific Ocean side of western Japan, while it decreases by $0.1-0.2 \mathrm{~K} \mathrm{~km}^{-1}$ in the other areas around the Japan Islands. These changes strongly influence the UP in July around the Japan Islands (Fig. 6). Fundamentally, the increase of the $\theta_{\text {emax }}$ between June and July makes the appearance of the UP more frequently, and that of the $\Gamma$ on the Pacific Ocean 
(a) $700 \mathrm{hPa}$ Temp

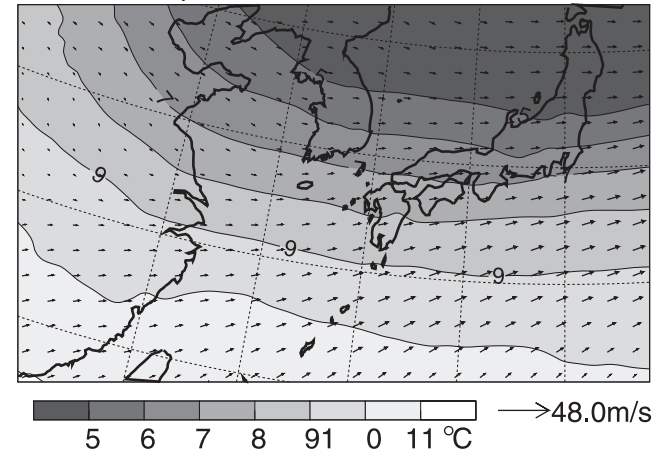

(b) $500 \mathrm{hPa}$ Temp

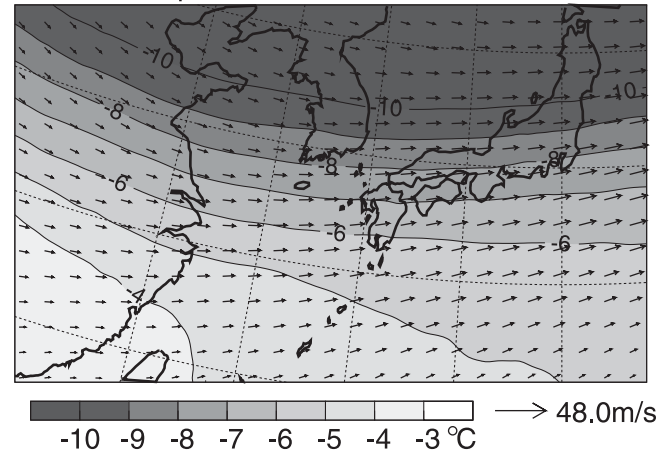

(c) $500 \mathrm{hPa} \mathrm{RH}$



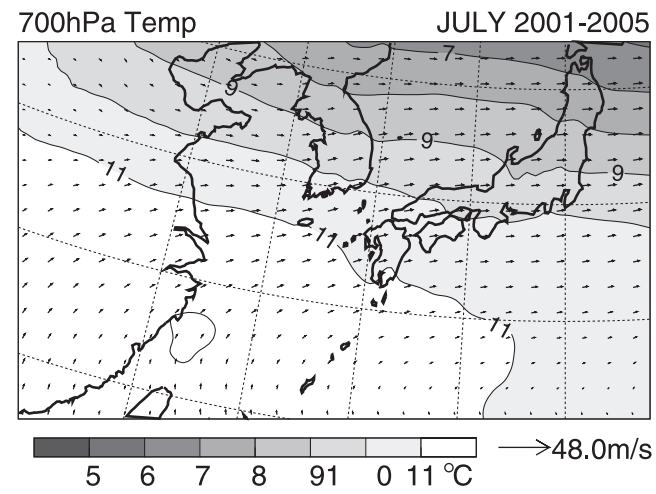


Fig. 8. Same as Fig. 7, but for (a) the $700 \mathrm{hPa}$-level temperature, (b) the $500 \mathrm{hPa}$-level temperature and (c) the $500 \mathrm{hPa}-$ level relative humidity. Vectors present the horizontal winds at the same level.

side of western Japan enhances it (Fig. 6a). Meanwhile the appearance of the UP in the other areas around the Japan Islands is suppressed by the decrease of the $\Gamma$ (Figs. $6 \mathrm{~b}$ and $6 c)$.

The cause for the change of the $\Gamma$ between June and July around the Japan Islands is examined from the atmospheric conditions below a level of $500 \mathrm{hPa}$. Figure 8 shows the averaged fields of the $700 \mathrm{hPa}-$ level $T$, the $500 \mathrm{hPa}$-level $T$, and the $500 \mathrm{hPa}$-level $\mathrm{RH}\left(\mathrm{RH}_{500}\right)$ in June and July between 2001 and 2005. The iso- therms at a level of $700 \mathrm{hPa}$ around the Japan Islands in June lie in almost an east-west direction, while the gradient of the $T$ in a southnorth direction in July becomes small on the Pacific Ocean side of western Japan (Fig. 8a). These features can be explained by the wind vectors in Fig. 8a. In June, strong westerly winds are found around the Japan Islands, and they transport an air over the China Continent to the Japan Islands. Meanwhile on the Pacific Ocean side of western Japan in July, westerly winds are relatively weak, because 
the Pacific high pressure zone frequently covers there.

The $500 \mathrm{hPa}$-level $T$ (Fig. 8b) is highest over the southern part of China, and the area with the highest $T$ shifts northward between June and July. The warmed atmospheric condition is produced mainly below a level of $500 \mathrm{hPa}$, through the release of latent heat associated with convective activities. This can be ascertained from the correspondence of the area with the highest $T$ to that with high $\mathrm{RH}_{500}$ (Fig. 8c), because convective activities transport low-level water vapor to the middle level. Therefore, the northward movement of the area with the highest $T$, over the southern part of China, is associated with that of the Baiu frontal zone (Meiyu one in China).

From the above-mentioned results, it can be concluded that a middle-level air, warmed through convective activities over the China Continent, is frequently transported by westerly winds to the Japan Islands, and it decreases the $\Gamma$ below the middle level. On the Pacific Ocean side of western Japan in July, however, the frequency of such transportation becomes lower, and consequently the averaged $\Gamma$ becomes relatively larger. It should be noted that the warmed air transported to eastern Japan is produced not necessarily over the China Continent, but also in western Japan. This is because convective activities are also strong over western Japan during the Baiu season, especially in July.

\subsection{Factors to determine the LNB}

The vertical profiles of the appearance rate of the LNB shown in Fig. 4 can not be explained by the averaged environmental fields, such as
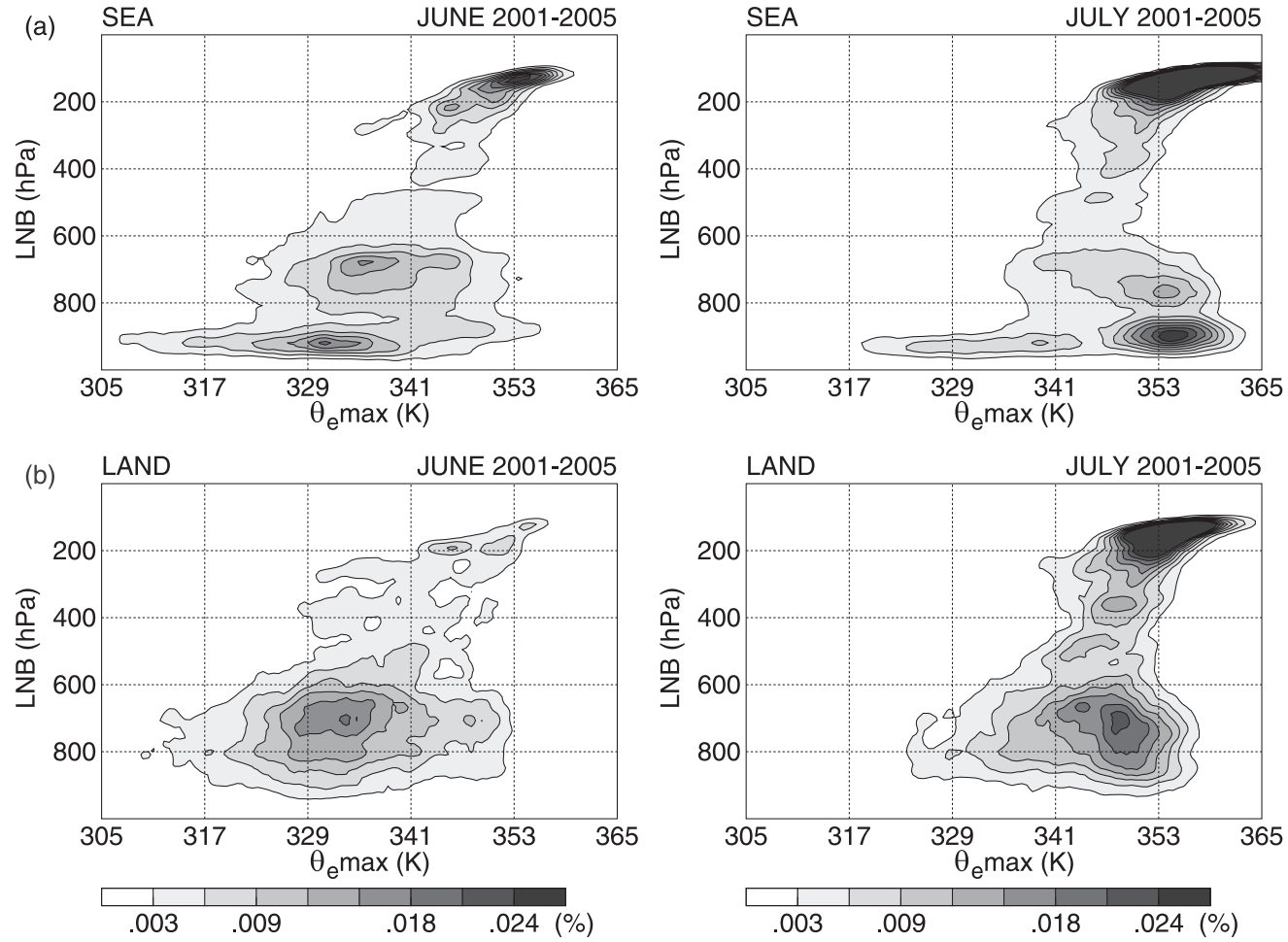

Fig. 9. Distributions of the appearance rate of the LNB for the maximum potential temperature $\left(\theta_{\text {emax }}\right)$, estimated by lifting an air with the maximum equivalent potential temperature, (a) over the sea and (b) on the land around the Japan Islands, domain (1) in Fig. 2, in June (left panel) and July (right panel) between 2001 and 2005. Regional analysis data of the JMA is used in this estimation. Each rate is calculated by dividing the LNB into 100 vertical levels with an interval of $1 \mathrm{hPa}$ in an axis of the ordinate, and the $\theta_{\text {emax }}$ between $305 \mathrm{~K}$ and $365 \mathrm{~K}$ into 100 classes with an interval of $0.06 \mathrm{~K}$ in an axis of the abscissa. 

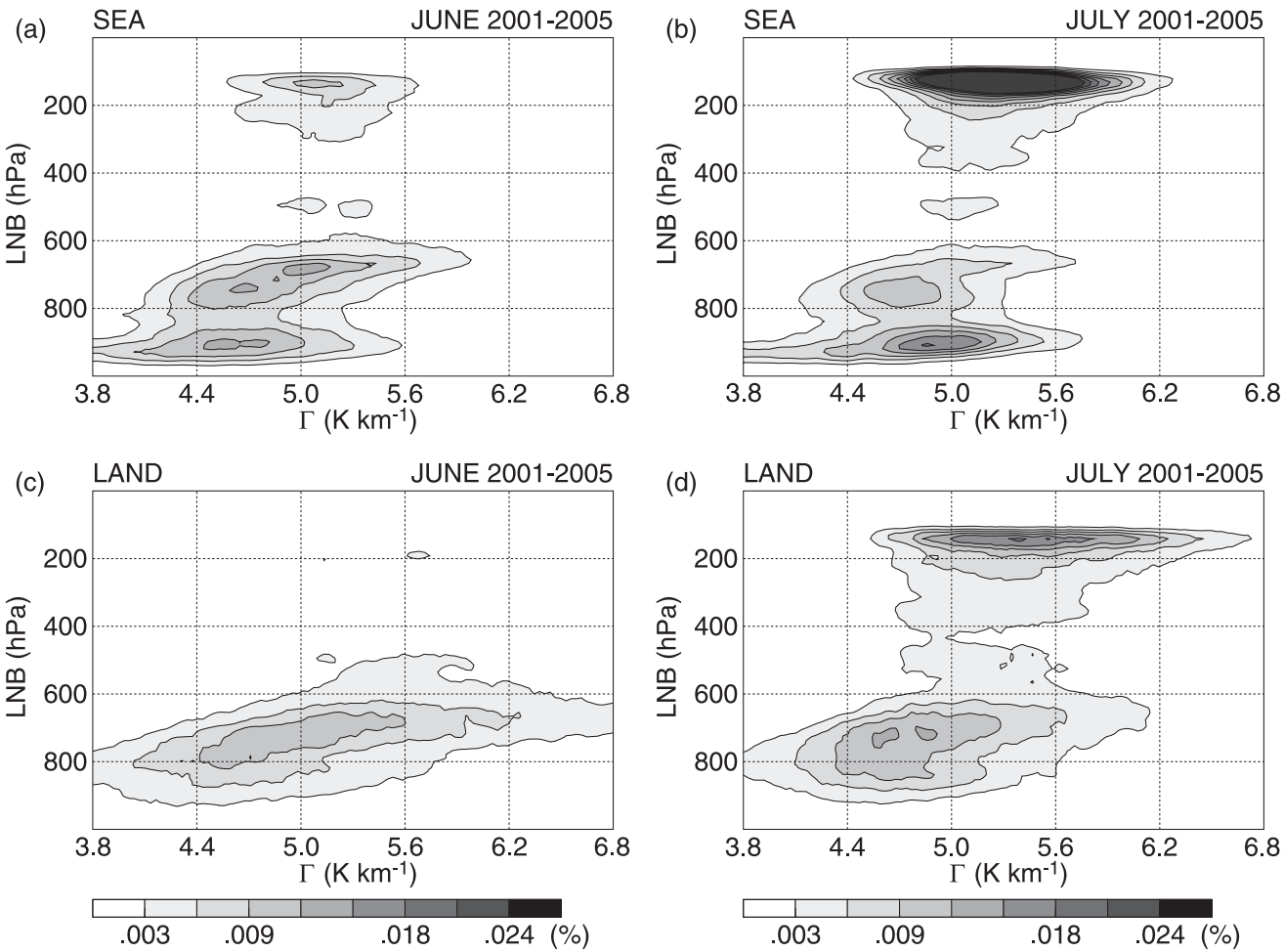

Fig. 10. Same as Fig. 9, but by dividing the lapse rate between an about 500-m altitude and a 700$\mathrm{hPa}$ level into 100 classes between $3.4 \mathrm{~K} \mathrm{~km}^{-1}$ and $6.4 \mathrm{~K} \mathrm{~km}^{-1}$ with an interval of $0.03 \mathrm{~K} \mathrm{~km}^{-1}$.

those shown in Figs. 7 and 8. In this subsection, individual atmospheric conditions for each calculated LNB are statistically examined focusing on the inflow of low-level humid and middle-level warmed airs (i.e., the $\theta_{\text {emax }}$ and the averaged $\Gamma$ between lower and middle levels), and factors to determine the LNB are investigated to clarify the reason why it is remarkably divided into the UP and MP.

The inflow of a low-level humid air makes the LNB higher (see Fig. 1b). The influence of this inflow on the LNB is examined using the appearance rate of high $\theta_{e \max }$. Figure 9 shows the distributions of the appearance rate of the LNB for the $\theta_{\text {emax }}$ over the sea and on the land around the Japan Islands, in June and July between 2001 and 2005. This figure is produced by subdividing the vertical profile of the LNB, shown in Fig. 4, with the $\theta_{\text {emax }}$ into 100 classes between $305 \mathrm{~K}$ and $365 \mathrm{~K}$, with an interval of $0.06 \mathrm{~K}$ in an axis of the abscissa. In June, the UP and MP over the sea can be almost separated with the threshold of the $\theta_{\text {e } \max }$ of $343 \mathrm{~K}$. In July, the UP appears over the sea and on the land only for the $\theta_{\text {emax }}$ higher than $360 \mathrm{~K}$ and $357 \mathrm{~K}$, respectively. The MP appears on the land only for $\theta_{\text {emax }}<341 \mathrm{~K}$. However, the UP and MP can not be divided for the other range of the $\theta_{\text {emax }}$.

As described in the Subsection 3.2, the inflow of a middle-level air, warmed through convective activities over upstream regions, especially the China Continent, strongly influences the $\Gamma$ around the Japan Islands. This influence is examined. Figure 10 shows the distributions of the appearance rate of the LNB for the $\Gamma$ averaged between about 500-m altitude and a 700$\mathrm{hPa}$ level, subdivided into 100 classes between $3.4 \mathrm{~K} \mathrm{~km}^{-1}$ and $6.4 \mathrm{~K} \mathrm{~km}^{-1}$ with an interval of $0.03 \mathrm{~K} \mathrm{~km}^{-1}$. It is clearly found that the MP is distributed with a smaller $\Gamma$ than the UP. The threshold of the $\Gamma$ for the separation of the MP and UP is about $5.0 \mathrm{~K} \mathrm{~km}^{-1}$, although the appearance of the LNB can not be completely separated by using it. In June most of the LNB over the sea can be roughly separated by using the threshold, while it scarcely appears at the UP on the land, even for the $\Gamma$ larger than the 

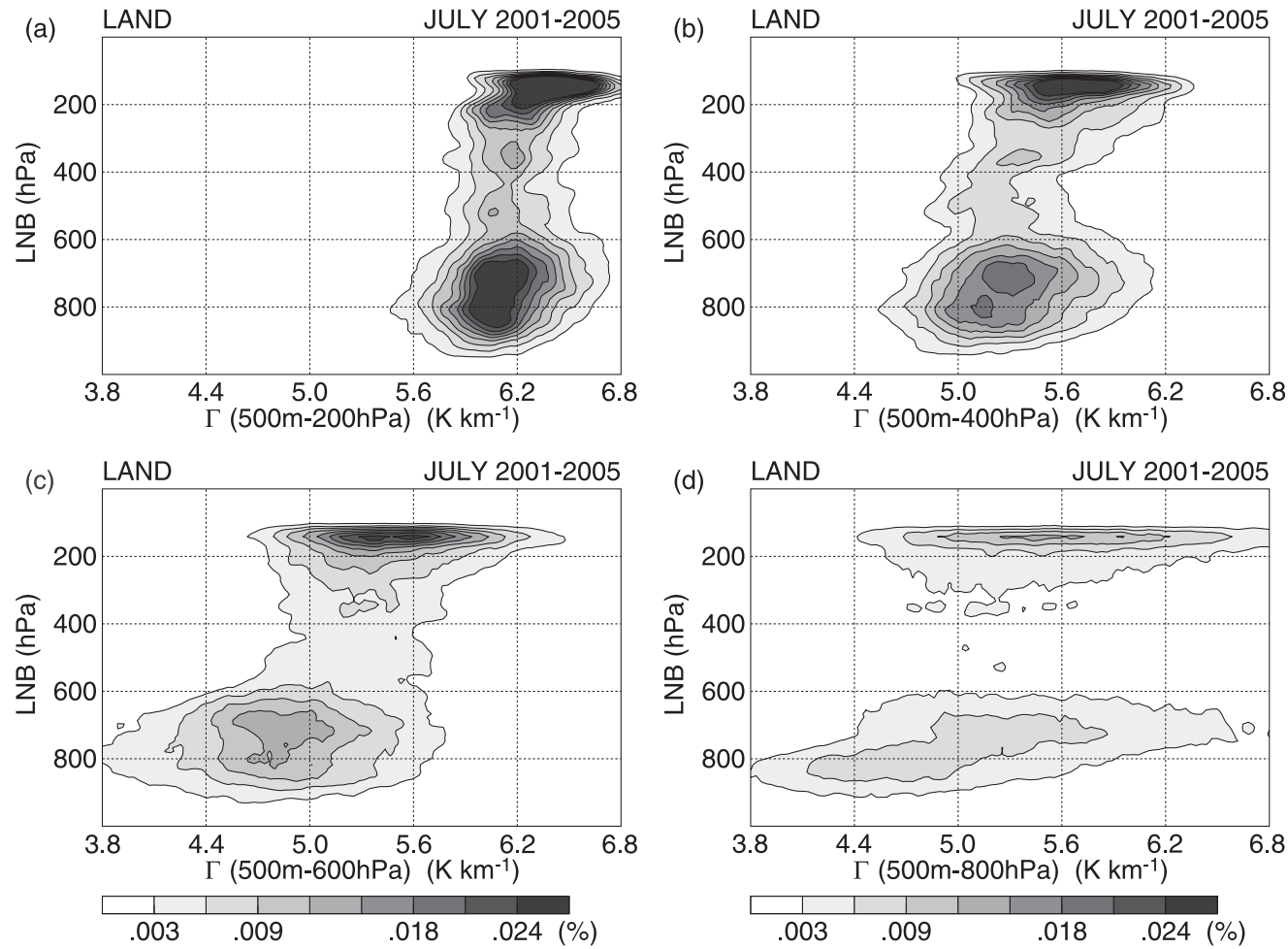

Fig. 11. Same as Fig. 10d, but the lapse rate between an about 500-m altitude and (a) $200 \mathrm{hPa}$, (b) $400 \mathrm{hPa}$, (c) $600 \mathrm{hPa}$, and (d) $800 \mathrm{hPa}$.

threshold (Fig. 10c). In July, most of the LNB both over the sea and on the land can be roughly separated by using the threshold. It should be noted that the MP becomes lower as the $\Gamma$ becomes smaller. This is because the MP can not exceed the highest LNB ( $\mathrm{LNB}_{\max }$ ), determined by the $\Gamma$ (see thin line in Fig. A2b). Moreover most of the $\Gamma$, larger than the threshold on the land, is brought from the development of the atmospheric boundary layer in the daytime (see Subsection 3.5).

The above-mentioned statistical results show that the determination of the LNB strongly depends on the intensity of the $\theta_{\text {emax }}$, and the averaged $\Gamma$ between lower and middle levels. From such averaged $\Gamma$, however, the atmospheric condition (i.e., the vertical profile of $T$ ) can not be characterized in detail. Therefore, the stratification to cause the UP or MP is examined from the other vertically averaged $\Gamma \mathrm{s}$.

Figure 11 shows the distributions of the appearance rate of the $\mathrm{LNB}$, for the $\Gamma \mathrm{s}$ averaged between about $500-\mathrm{m}$ altitude and $200-\mathrm{hPa}$, $400-\mathrm{hPa}, 600-\mathrm{hPa}$, and $800-\mathrm{hPa}$ levels on the land in July. For the other divisions in Fig. 10 (in June, and over the sea in July), the appearance rate of the UP and MP distributes with almost the same characteristic features as those in Fig. 11. The threshold of about $5.0 \mathrm{~K} \mathrm{~km}^{-1}$, for the separation of the MP and UP, can also be found in the distribution of the $\Gamma$ averaged between about $500-\mathrm{m}$ altitude and $600-\mathrm{hPa}$ level (Fig. 11c). Although the $\Gamma$ averaged between about 500-m altitude and other levels can not separate the MP and UP, it tends to be estimated slightly larger for the UP than for the MP (Figs. 11a, 11b and 11d). This means that the middle-level atmosphere around $600 \sim 700 \mathrm{hPa}$ becomes warmer when the LNB appears at the MP.

Last in this subsection, the relationship between the LNB and CAPE is examined. Figure 12 shows the distributions of the appearance rate of the LNB for the CAPE, subdivided into 100 classes between $0 \mathrm{~J} \mathrm{~kg}^{-1}$ and $2000 \mathrm{~J} \mathrm{~kg}^{-1}$ with an interval of $20 \mathrm{~J} \mathrm{~kg}^{-1}$. The CAPE for the MP is smaller than $200 \mathrm{~J} \mathrm{~kg}^{-1}$, while that for the UP is larger than $600 \mathrm{~J} \mathrm{~kg}^{-1}$, indepen- 

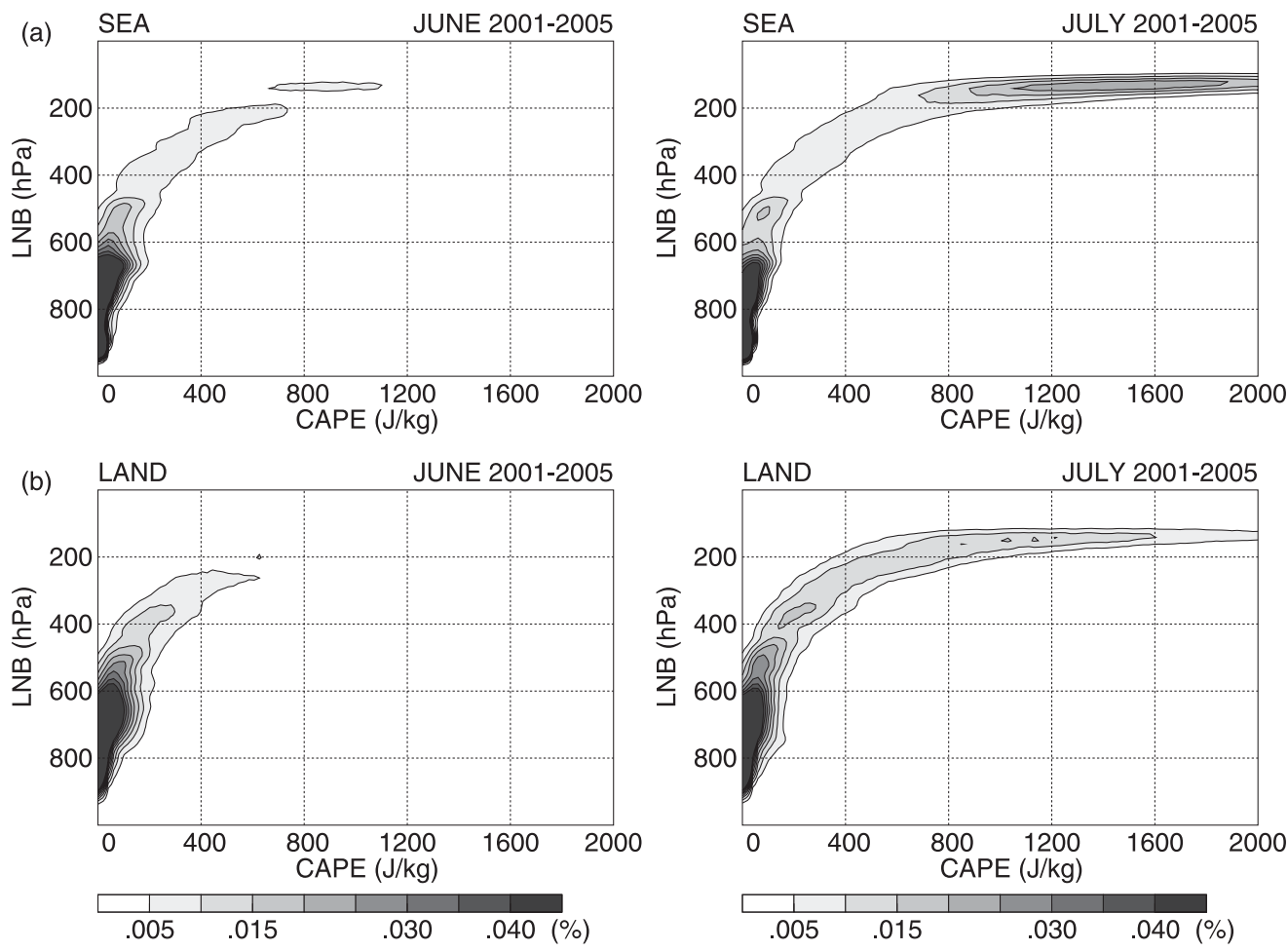

Fig. 12. Same as Fig. 9, but by dividing the CAPE into 100 classes between $0 \mathrm{~J} \mathrm{~kg}^{-1}$ and $2000 \mathrm{~J} \mathrm{~kg}^{-1}$ with an interval of $20 \mathrm{~J} \mathrm{~kg}^{-1}$.

dently of the seasonal change between June and July, and the difference between the sea and land. This relationship is natural, because the CAPE strongly depends on the LNB [see Eq. (2)]. Therefore the small values of the CAPE are calculated under the relatively stable atmospheric condition with a small $\Gamma$.

\subsection{Influence of the inflow of a middle-level dry air}

The previous studies (e.g., Kato and Aranami 2005; Kato 2006) pointed out that the inflow of a middle-level dry air was found, when heavy rainfall was observed. They also showed that the $T$ of the dry air was relatively higher than that of the surrounding. This indicates that the inflow of a middle-level dry air decreases the $\Gamma$ below the middle level. Its influence is examined statistically in this subsection.

Figures 13 and 14 show the distributions of the appearance rate of the LNB for the $\mathrm{RH}_{500}$ and the $700-\mathrm{hPa}$ level $\mathrm{RH}\left(\mathrm{RH}_{700}\right)$, subdivided into 90 classes between $0 \%$ and $90 \%$ with an interval of $1 \%$. The $\mathrm{RH}_{500}$ for the MP is consid- erably low $(<40 \%)$, especially in June (Fig. 13). This can be ascertained by the averaged field of the $\mathrm{RH}_{500}$, in which the $\mathrm{RH}$ around the Japan Islands, is lower than 50\% (Fig. 8c). The dry condition at a $500-\mathrm{hPa}$ level indicates that a warmed and humidified air over upstream regions (especially the China Continent), through convective activities, hardly flows around a $500-\mathrm{hPa}$ level over the Japan Islands, when the LNB is calculated at the MP. On the other hand, the UP is distributed independently of the $\mathrm{RH}_{500}$, but for the extremely dry condition.

The $\mathrm{RH}_{700}$ for the MP is distributed mainly between $40 \%$ and $80 \%$ (Fig. 14). This indicates that a warmed and humidified air is transported from upstream regions into a level around $700 \mathrm{hPa}$ over the Japan Islands, when the LNB is calculated at the MP. It should be noted that a $700 \mathrm{hPa}$-level air is also warmed over western Japan, and it also influences the atmospheric condition over eastern Japan, as described in Subsection 3.2. The influence of a $700 \mathrm{hPa}$-level dry air on the LNB is found in the decline of the MP, associated with the de- 

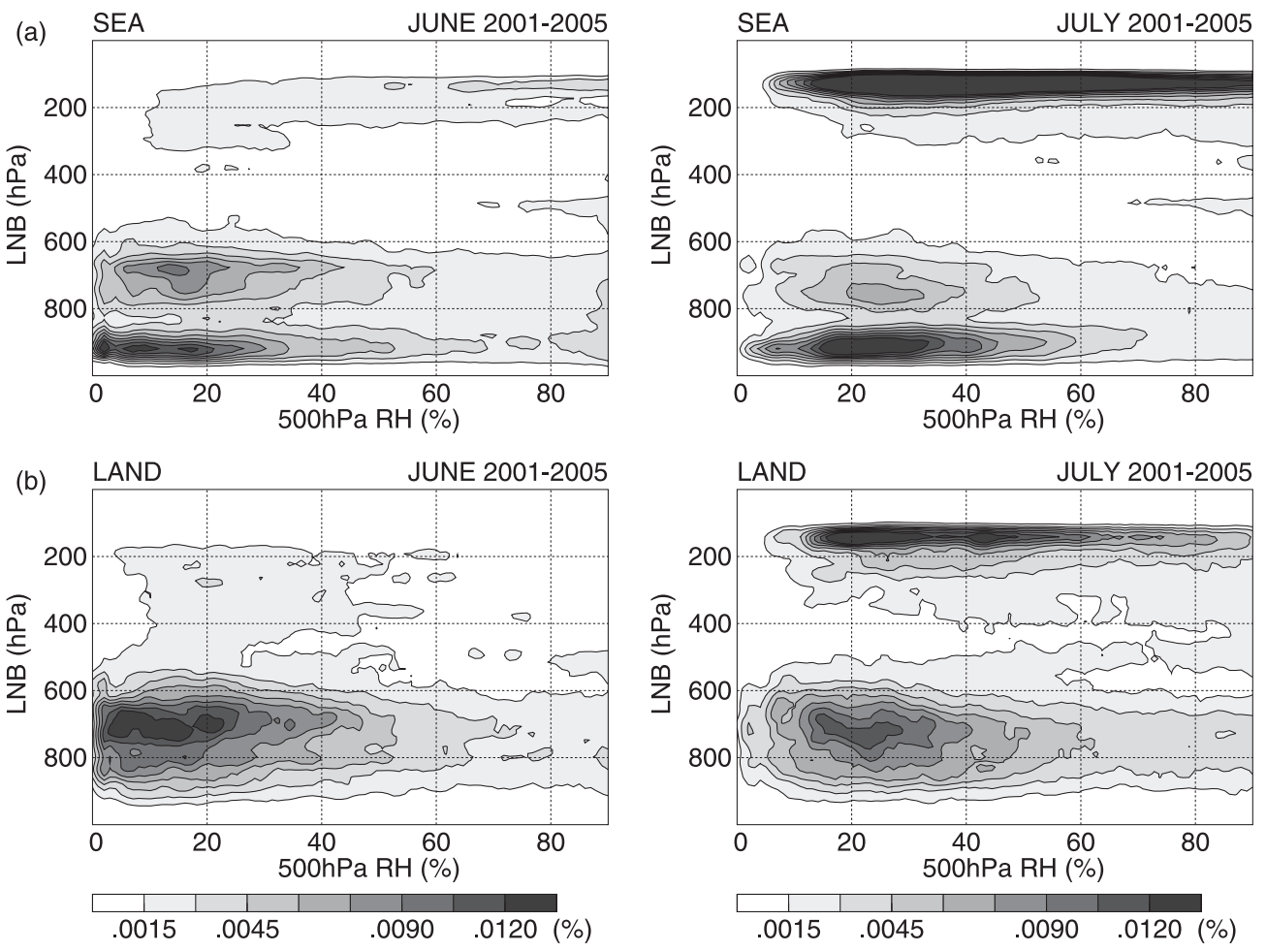

Fig. 13. Same as Fig. 9, but by dividing the $500 \mathrm{hPa}$-level relative humidity into 90 classes between $0 \%$ and $90 \%$ with an interval of $1 \%$.

crease of $\mathrm{RH}$. Therefore a $700 \mathrm{hPa}$-level dry air lowers the LNB that appears at the MP, i.e., it suppresses the development of cumulonimbi. On the other hand the UP in June is found for $\mathrm{RH}_{700}>50 \%$. This indicates that the LNB never appears at the UP in June, when an extremely dry air flows into the middle level.

From the above-mentioned statistical results, the inflow of a middle-level dry air is one of the factors to determine the LNB, but its influence on the LNB is considerably smaller than that of a middle-level warmed air transported from upstream regions. However the inflow of a middle-level dry air often maintains convective activities through the evaporation cooling of hydrometeors, although it suppresses the development of cumulonimbi, as emphasized by Kato (2006).

\subsection{Annual and diurnal variations}

The annual variation of the appearance rate of the LNB is examined in relation to convective activities over upstream regions, especially the southern part of China. Figures 15 and 16 show the annual mean of its vertical profiles and the $\mathrm{RH}_{500}$ distributions in June and July between 2001 and 2005, respectively. Major features of the UP, MP, and LP described in Subsection 3.1 are found in each year (Fig. 15). The area with the highest $\mathrm{RH}_{500}$ is found over the southern part of China in each June, and it shifts northward in July, but for 2001 and 2002 (Fig. 16).

In June the UP is not clear on the land, but in $2004^{7}$. This is caused by the decrease of the $\Gamma$ below the middle level, around the Japan Islands, brought from the inflow of a middle-level air that is warmed through convective activities over upstream regions, especially the southern part of China (see the $\mathrm{RH}_{500}$ higher than $70 \%$ in Fig. 16a). The UP over the sea can be distinguished in 2001 and 2003, in addition to 2004 (Fig. 15a). This distinguished UP is found over the area south of the Japan Islands

7 In June 2004, two typhoons landed on the Japan Islands, and they produced the environmental field with high LNB. 

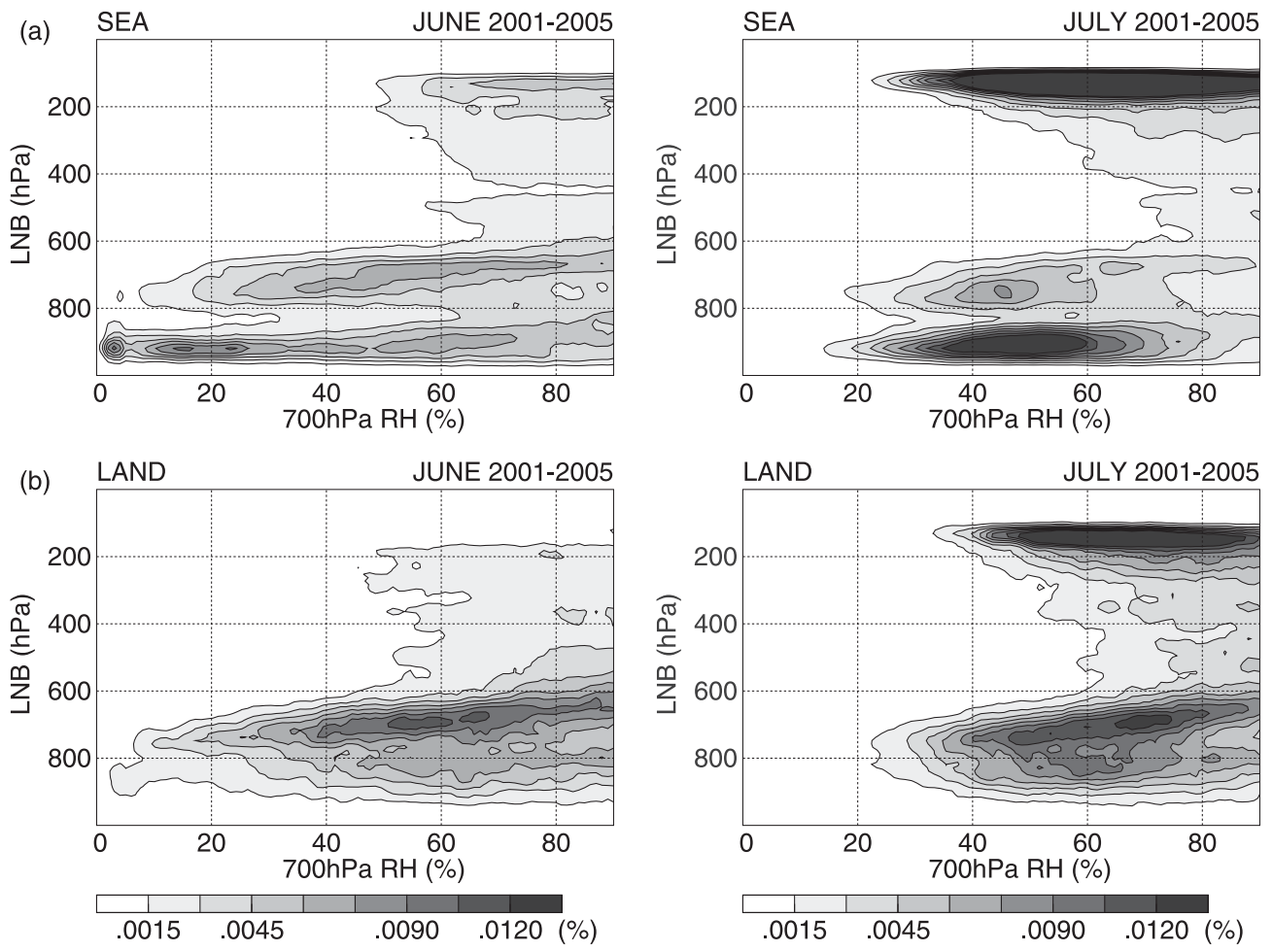

Fig. 14. Same as Fig. 13, but for the $700 \mathrm{hPa}$-level relative humidity.

(domain (1)-1, not shown). The middle-level humid area around the Japan Islands in 2001 and 2003 is located northward, in comparison with that in 2002 and 2005 (Fig. 16a). This indicates that a middle-level warmed air sometimes made no influence on the LNB over the area south of the Japan Islands in 2001 and 2003, such as found in July.

On the other hand, in July the synoptic field around the Japan Islands can be divided into the following two patterns from the circulation of middle-level winds (Fig. 16b). One is such a pattern with predominant westerly winds as found in June (in 2003 and 2005), and the other is the pattern with northward extension of the Pacific high pressure zone (in 2001 and 2004). The synoptic field in 2002 has features combined of two patterns. The appearance rate of the LNB at the UP in the pattern with northward extension of the Pacific high pressure zone is considerably higher than that in the pattern with predominant westerly winds, especially on the land. This is because the northward extension of the Pacific high pressure zone prevents the inflow of a warmed middle- level air into the Japan Islands, produced by strong convective activities over the southern part of China. Under such atmospheric conditions, heavy rainfall was often observed even on the Japan Sea side of the Japan Islands in July 2004 (e.g., see Kato and Aranami 2005).

From the results for the annual variation (Figs. 15 and 16), it is indicated that the LNB around the Japan Islands during the Baiu season strongly depends on convective activities over the southern part of China. In July, however, the northward extension of the Pacific high pressure zone also influences the LNB, especially the appearance rate at the UP.

Next the cause that produces the difference in the vertical profiles of the appearance rate of the LNB between the sea and the land, shown in Fig. 4, is examined from the diurnal variation of the LNB. Figure 17 shows the diurnal variation of the appearance rate of the LNB in June and July between 2001 and 2005, obtained from the RANAL at four times of 09 JST, 15 JST, 21 JST and 03 JST.

On the land the MP appears most frequently at $15 \mathrm{JST}$, and its appearance rate is lowest at 

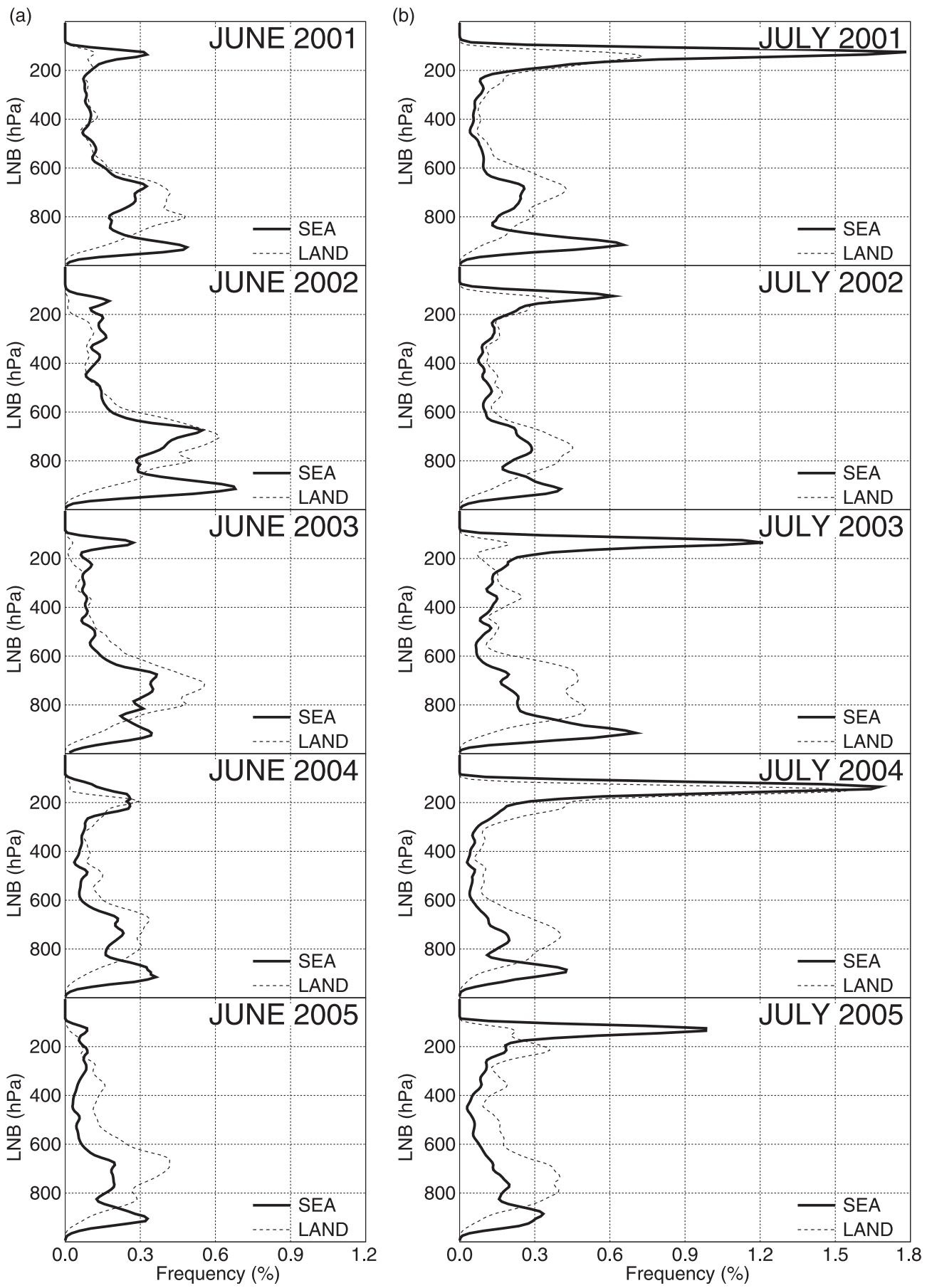

Fig. 15. Same as Fig. 4, but for the annual mean in (a) June and (b) July between 2001 and 2005.

03 JST. In July, the UP at 21 JST appears with almost the same high frequency as that at 15 JST. The solar radiation in the daytime develops the atmospheric boundary layer, and consequently the $\theta_{\text {emax }}$ increases to often make the atmospheric condition latently unstable. On the other hand, the $\theta_{\text {emax }}$ decreases at night due to the long wave radiation. This diurnal variation of the $\theta_{e \max }$ causes that of the appearance rate of the LNB. It should be noted 
(a) $500 \mathrm{hPa} \mathrm{RH}$



(b) $500 \mathrm{hPa} \mathrm{RH}$

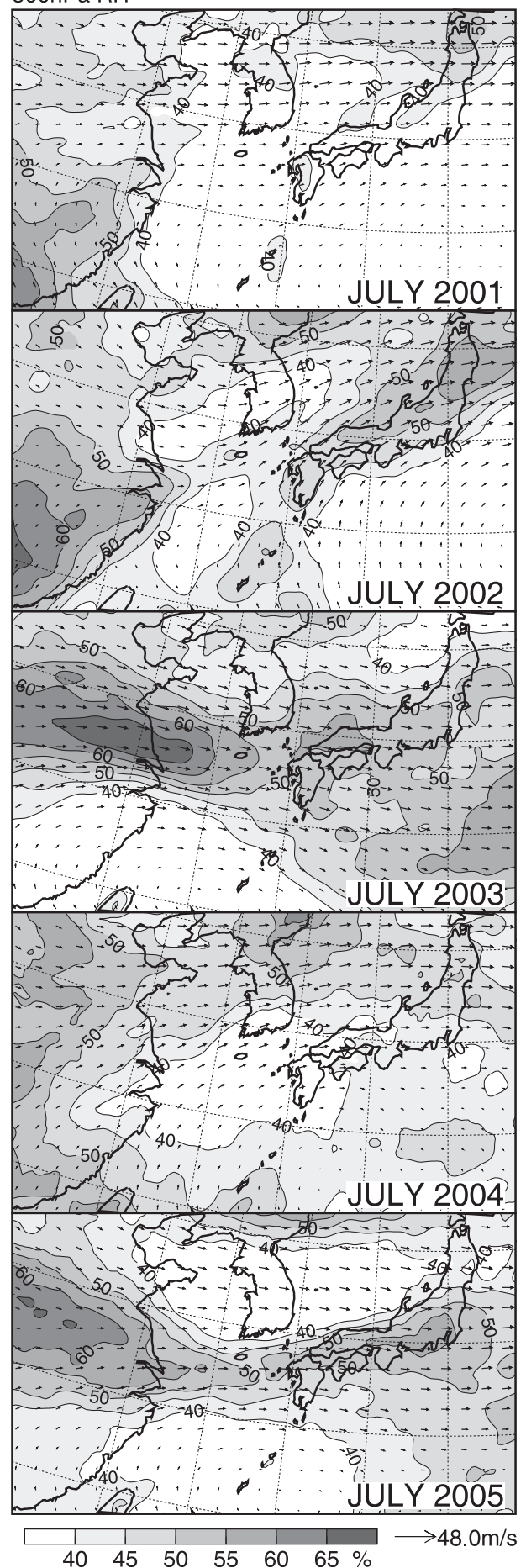

Fig. 16. Same as Fig. 8c, but for the annual mean in (a) June and (b) July between 2001 and 2005. 



Fig. 17. Same as Fig. 4, but for the diurnal variation in (a) June and (b) July, obtained from the appearance rates at four analysis times of 09 JST, 15 JST, 21 JST and 03 JST.

that the vertical levels of both the UP and MP hardly change in the diurnal variation. This is because the level with the minimum $\theta_{e}^{*}\left(L \theta_{e m i n}^{*}\right)$ hardly changes for the development of the atmospheric boundary layer. The $\Gamma$ below the $L \theta_{\text {emin }}^{*}$ becomes large, associated with the raise of low-level $T$, due to the solar radiation. However, when the atmospheric boundary layer develops over the $L \theta_{e m i n}^{*}$, the $L \theta_{e \text { min }}^{*}$ shifts upward. This shift is often analyzed in the afternoon, especially between 15 JST and 21 JST in this study (not shown). Consequently the appearance rate at the UP maintains between $15 \mathrm{JST}$ and $21 \mathrm{JST}$, while that at the MP decreases.

On the contrary, over the sea the UP and LP appear most frequently at 03 JST, although the diurnal variation of the appearance rate of the LNB is smaller than that on the land. The diurnal variation of the MP is further smaller. The highest appearance rate in the UP and LP at 03 JST is brought from the increase of the $\theta_{\text {emax }}$ (not shown). However, the increase of the $\theta_{e \max }$ is small, because the diurnal varia- 
tion of the sea surface temperature is about $0.6-0.8 \mathrm{~K}$ around western Japan (Kawai and Kawamura 2005). This is the reason for the small diurnal variation of the appearance rate of the LNB over the sea.

Previous studies (e.g., Kurihara and Kato 1997; Hirose and Nakamura 2005) showed that the peak in the diurnal variation of rainfall amount, in western Japan during the Baiu season, was found in the early morning. This peak could be caused mainly by the long wave radiation for clouds (Kato 1999). However, the increase of the appearance rate at the UP at night over the sea could be also one of the factors to cause the peak in the diurnal variation of rainfall amount during the Baiu season.

\section{Results for the other areas}

In order to find common features to the LNB around the Japan Islands, the LNB in the other areas around the Baiu frontal zone is examined comparing with the statistical results described in Section 3. Figure 18 shows the vertical profiles of the appearance rate of the LNB around the Okinawa Islands (domain (2) in Fig. 2), the southern part of China, (domain (3), the northern part of China (domain (4), and Korea (domain (5)) in June and July between 2001 and 2005. The vertical levels at which the UP, MP and LP appears are almost the same as those around the Japan Islands (Fig. 4).

Around the Okinawa Islands (Fig. 18a), the MP is relatively weak in comparison with that around the Japan Islands (Fig. 4), and the appearance rate at the MP $(\sim 0.3 \%)$ is also smaller than that around the Japan Islands $(\sim 0.4-0.5 \%)$. This smaller rate at the MP is caused by higher $\theta_{\text {emax }}$ than that around the Japan Islands (see Fig. 7b), which is produced by higher sea surface temperature (not shown). As described in Subsection 3.3, the LNB never appears at the MP for the $\theta_{\text {emax }}$ higher than $360 \mathrm{~K}$ (see Fig. 9). Around the southern part of China (Fig. 18b), the appearance rate at the MP $(\sim 0.3 \%)$ is also smaller than that around the Japan Islands (Fig. 4). This is because convective activities are limited upstream of the southern part of China.

Even in June the UP appears with higher frequency around the Okinawa Islands and the southern part of China, because the $\theta_{e \max }$ is higher and the influence of upstream convec- tive activities in the domain (3) is smaller than those around the Japan Islands, respectively. Under such atmospheric conditions, convective activities become strong over the southern part of China. However convective activities around the Okinawa Islands do not become so strong, because there little exists forcing that can lift a low-level humid air to the LFC under the influence of the Pacific high pressure zone. Since the northern part of Taiwan Island with high terrains is included into the domain (2) (see Fig. 2 ), the appearance rate at the UP on the land is considerably smaller around the Okinawa Islands than that over the sea (Fig. 18a).

Over the northern part of China (Fig. 18c), the appearance rate at the MP is lower than that around the Japan Islands (Fig. 4), while the MP extends upward maintaining almost the same appearance rate as found around $700 \mathrm{hPa}$. This indicates that the cloud top heights of cumulonimbi that develop associated with the MP are higher than those around the Japan Islands, and some of them exceed a level of $500 \mathrm{hPa}(\sim 6 \mathrm{~km})$. Zhang et al. (2006) pointed out that such cumulonimbi, defined as the CMD, are frequently observed over the northern part of China in June and July. They also showed that the deep convection appears with less frequency than the CMD, although the appearance rate at the UP is considerably higher than that at the MP. In June the appearance rate at the UP on the land is higher than that around the Japan Islands (Fig. 4), because the atmospheric boundary layer often develops higher over the northern part of China that is almost located north of the Baiu frontal zone (Fig. 16a).

Around Korea (Fig. 18d), the vertical profiles of the appearance rate of the LNB are very similar to that on the Japan-sea side of western Japan (Fig. 6b), because Korea is located downward of the area with strong convective activities (especially the China Continent) and the Pacific high pressure zone scarcely extends there until late July. The UP on the land shifts slightly to the lower level in comparison with that in the other areas. This is because the lower $T$ at the low level decreases the $\mathrm{LNB}_{\max }$ (see Fig. A2). Such lowering of the LNB is also found over the northern part of China (Fig. 18c).

The characteristic features of the LNB over the western part of the North Pacific Ocean 



Fig. 18. Same as Fig. 4, but around (a) the Okinawa Islands, domain (2) in Fig. 2, (b) the southern part of China, domain (3), (c) the northern part of China, domain (4), and (d) Korea, domain (5). Scales in the frequency (abscissa) in (a) and (b) is different from those in Fig. 4. 



Fig. 19. (a) Same as Fig. 4, but for the western part of North Pacific Ocean, domain (6) in Fig. 2. (b) Same as Fig. 5, but for upper-air sounding at Chichijima, whose location is shown by a white triangle in Fig. 2. Broken and solid lines denotes the appearance rate in June and July, respectively.

are examined to find differences from those around the Baiu frontal zone. Figure 19a shows the vertical profiles of the appearance rate of the LNB in the domain (6) in Fig. 2. The vertical profiles are almost the same in both June and July, and they have two peaks of the UP and LP. Especially the UP appears with extremely high frequency. On the other hand, the MP is not found, although the LNB appears even in the layer between levels of $800 \mathrm{hPa}$ and $700 \mathrm{hPa}$. These features can be ascertained by the LNB that is estimated from upper-air sounding data at Chichijima (shown by a white triangle in Fig. 2), although the appearance rate is about a half (Fig. 19b). It should be noted that the LNB scarcely appears between $700 \mathrm{hPa}$ and $300 \mathrm{hPa}$ over the western part of the North Pacific Ocean, while it appears with low frequency $(0.1 \sim 0.2 \%)$ at that vertical layer around the Baiu frontal zone (Figs. 4 and 18). This might be brought from the low accuracy of the RANAL over the North Pacific Ocean due to few upper-air sounding observations, because the LNB at Chichijima is also estimated with low frequency $(\sim 0.1 \%)$ between $700 \mathrm{hPa}$ and $300 \mathrm{hPa}$. However major features found in the vertical profiles of the appearance rate of the LNB are independent of the accuracy of the RANAL.

The above-mentioned statistical results show that the MP found in the appearance rate of the LNB is one of the characteristic features around the Baiu frontal zone. Cumulonimbi that develop associated with the MP could be predominantly observed around the Baiu frontal zone, especially in June. In the next section, this is examined from two case studies on heavy rainfall events observed in June and July.

\section{Case studies}

The LNB roughly suggests cloud top heights of cumulonimbi or moist convection. However, the relationship between the LNB and cloud top heights can not be examined from the present statistical study on the LNB. In this section, therefore, the development of cumulonimbi for heavy rainfall cases is examined comparing the LNB distribution that is estimated from the RANAL. Heavy rainfall events selected in this study were observed over the Niigata area, the middle part of the Japan Islands, in July 2004 and June 2005.

Figure 20 shows the 6-houly accumulated rainfall charts, depicted from the RadarRaingauge analyzed precipitation, between 06 JST and 12 JST on 13 July 2004 and 28 June 2005. The Radar-Raingauge analyzed precipitation is estimated by meteorological radars, and calibrated by surface rain gauge observations. In the case of July 2004 (Fig. 20a), a band-shaped rainfall area with a length exceeding $200 \mathrm{~km}$ and a width of $20 \mathrm{~km} \sim 30 \mathrm{~km}$ is found. Rainfall amount is extremely large on the downstream (eastern) side of this area. The area with rainfall amount exceeding $200 \mathrm{~mm}$ $(6 \mathrm{~h})^{-1}$ is localized. The extremely large rainfall was caused by the stagnancy of the bandshaped rainfall area (not shown).

On the other hand, such a localized area with extremely large rainfall is not found in the case of June 2005, although a band-shaped 
(a)

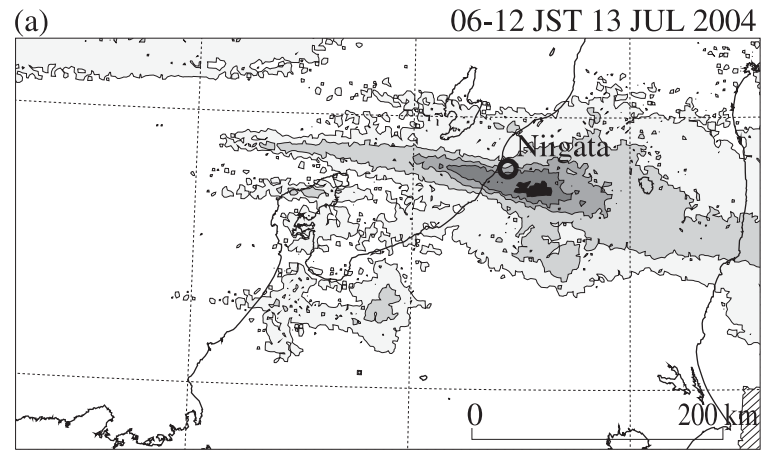

(b)

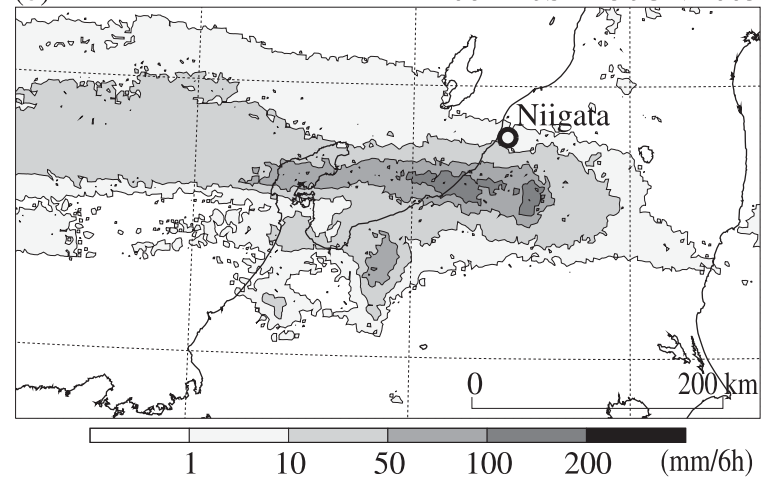

Fig. 20. 6-houly accumulated rainfall charts, estimated from the RadarRaingauge analyzed precipitation, between 06 JST and 12 JST on (a) 13 July 2004 and (b) 28 June 2005.

rainfall area also formed (Fig. 20b). This is because the band-shaped rainfall area did not stagnate, and it slowly moved southward (not shown). However since the area with rainfall amount exceeding $50 \mathrm{~mm}(6 \mathrm{~h})^{-1}$ extends widely in the case of June 2005, total rainfall amount over the Niigata area is comparable with the case of July 2004.

Figure 21 shows the surface weather charts at 09 JST on 13 July 2004 and 28 June 2005. In both cases, the stationary Baiu front is analyzed in an east-west direction across the Niigata area, and the Pacific high pressure zone extends northward to western Japan. This pressure pattern indicates that a low-level humid air, passing around the Pacific high pressure zone, can flow into the Niigata area.

Figure 22 shows the horizontal distributions of the LNB, the $\theta_{\text {emax }}$ and the $\Gamma$ between about $500-\mathrm{m}$ altitude and a $700-\mathrm{hPa}$ level at 09 JST on 13 July 2004 and 28 June 2005, depicted (a)



(b)



Fig. 21. Surface weather charts at 09 JST on (a) 13 July 2004 and (b) 28 June 2005 .

from the RANAL. In both cases, the LNB is estimated widely even over the area with rainfall (Fig. 22a). This means that heavy rainfall was caused under the latently unstable atmospheric condition, which maintained in spite of the existence of convective activities. In the case of July 2004, the LNB around the band-shaped rainfall area is higher than $250 \mathrm{hPa}$, while it is between $400 \mathrm{hPa}$ and $550 \mathrm{hPa}$ in the case of June 2005 (see dashed ellipses in Fig. 22a). This indicates that cumulonimbi developed higher in the case of July 2004 than in the case of June 2005. Kato and Goda (2001) con- 
(a) LNB 09JST 13 July 2004 LNB 09JST 28 June 2005


(b) $\theta \mathrm{e} \max$

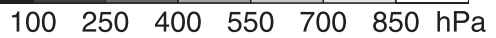

$\begin{array}{lllllll}100 & 250 & 400 & 550 & 700 & 850 \mathrm{hPa}\end{array}$



$340342344346348350 \mathrm{~K}$

(c) $\Gamma(500 \mathrm{~m}-700 \mathrm{hPa})$ 09JST 13 July $2004 \Gamma(500 \mathrm{~m}-700 \mathrm{hPa})$


Fig. 22. Horizontal distributions of (a) the LNB, (b) the maximum equivalent potential temperature and (c) the lapse rate between a about 500-m altitude and a 700-hPa level at 09 JST on 13 July 2004 (left panels) and (b) 28 June 2005 (right panels), depicted from regional analysis data of the JMA. The LNB is estimated by lifting an air with the maximum equivalent potential temperature. Dashed circles and crosses in (a) present the area with strong precipitation and the positions of lightning that were observed between 06 JST and 12 JST, respectively. Vectors in (b) present the horizontal winds at a height of about $500 \mathrm{~m}$.

cluded that the development of cumulonimbi is necessary for the stagnation of MCSs that generate a band-shaped heavy rainfall area. Therefore the higher development of cumulonimbi could cause localized heavy rainfall in the case of July 2004.

Factors to determine the distributions of the LNB are examined. The difference of the $\theta_{e \max }$ between the cases of July 2004 and June 2005 $(\sim 2 \mathrm{~K})$ is too small not to cause that of the LNB (Fig. 22b). On the other hand, the $\Gamma$ in the case of July 2004 is larger by about $0.4 \mathrm{~K} \mathrm{~km}^{-1}$ than that in the case of June 2005 (Fig. 22c). Therefore, the larger $\Gamma$ in the case of July 2004 mainly causes the higher LNB, as described in the former sections.

Last, the development of cumulonimbi is ascertained from the distribution of observed 
lightning to examine the relationship with the LNB. The electrical charge to generate lightning is made in the separation process, such as collision and rebound between graupel and cloud ice (or snow), above a height with the $T$ lower than $-10^{\circ} \mathrm{C}$ (Takahashi 1984). This height is about $6 \sim 7 \mathrm{~km}$ around the Baiu frontal zone. Therefore, the lightning is observed only in the case that cumulonimbi develop considerably higher than a height of $6 \mathrm{~km}$.

In Fig. 22a, the observed positions of lightning are also shown by crosses. In the case of July 2004, much lightning was observed around the band-shaped rainfall area. Meanwhile, the observed number of lightning is considerably small in the case of June 2005, especially on the downstream side of the bandshaped rainfall area. The areas with much observed number of lightning almost correspond to the distribution with the LNB higher than $400 \mathrm{hPa}$. These results indicate that many cumulonimbi in the case of July 2004 developed higher than those in the case of June 2005. Such difference found in the development of cumulonimbi could characterize the difference of heavy rainfall between June and July during the Baiu season.

\section{Conclusions and discussion}

In this study, cloud top heights of cumulonimbi around the Japan Islands during the Baiu season are examined statistically, using the level of neutral buoyancy (LNB) that is estimated from objective analysis data with the horizontal resolution of $20 \mathrm{~km}$. The statistical period is two months consisting of June and July in 2001-2005, and the LNB estimated in the case that the level of free convection (LFC) is more distant by $200 \mathrm{hPa}$ than the originating level of a lifted air is excluded from the statistics. The LNB is calculated for all horizontal grid points of objective analysis data, by lifting an air with the maximum equivalent potential temperature $\theta_{\text {emax }}$ below a level of $800 \mathrm{hPa}$, and searching the vertical level at which the saturated potential temperature $\theta_{e}^{*}$ of objective analysis data is equal to the $\theta_{e \max }$.

Three and two peaks are found in the vertical profiles of the appearance rate of the LNB over the sea and on the land, respectively. The upper-level peak (UP: $\sim 150 \mathrm{hPa}$ ) is very weak in June, and it is remarkably found in July.
The low-level peak (LP: $\sim 900 \mathrm{hPa}$ ) appears only over the sea, because it is caused by the development of the convectively mixed layer with almost the constant $\theta_{e}$ over the sea. The other peak is found at the middle level (MP: $\sim 700 \mathrm{hPa}$ ). In both June and July, the MP appears with higher frequency on the land than over the sea, because the development of the atmospheric boundary layer on the land increases the low-level $\theta_{e}$.

The formation mechanisms of the UP and MP in the vertical profiles of the appearance rate of the LNB around the Japan Islands are discussed using Fig. 23. The vertical profiles of $\theta_{e}^{*}$, in Figs. 23a and 23b (bold lines), are estimated from the peaks of the $\Gamma$ distributions in Figs. 10 and 11 for the UP and MP, respectively. Therefore, these profiles show the typical atmospheric conditions under which the LNB appears at the UP and MP. Here the discussion is focused on the level of the minimum $\theta_{e}^{*}\left(L \theta_{\text {emin }}^{*}\right)$. This level necessarily appears whenever the LNB can be estimated, and the LNB is higher than this level (Fig. A2a).

In Fig. 23a, since the $L \theta_{e \min }^{*}$ is found around $500 \mathrm{hPa}$, the LNB never appears at the MP. It should be noted that the $L \theta_{\text {emin }}^{*}$ for each LNB estimated at the UP is distributed between $700 \mathrm{hPa}$ and $300 \mathrm{hPa}$ (not shown). Moreover since the LNB estimated in the case that the LFC is more distant by $200 \mathrm{hPa}$ than the originating level of a lifted air is excluded from the statistics, the LNB also never appears below about $320 \mathrm{hPa}$. Consequently, the LNB appears at the UP under such atmospheric conditions, as shown in Fig. 23a.

The vertical profile of $\theta_{e}^{*}$ in Fig. 23b has two $L \theta_{\text {emin }}^{*}$ around $400 \mathrm{hPa}$ and $800 \mathrm{hPa}$, and a maximum around the layer between $600 \mathrm{hPa}$ and $700 \mathrm{hPa}$. This is consistent with the statistical results that the $L \theta_{\text {emin }}^{*}$ for each LNB estimated at the MP clearly appears in two layers below $600 \mathrm{hPa}$ and between $500 \mathrm{hPa}$ and $300 \mathrm{hPa}$ (not shown), and it could be caused by the effects of diabatic heating at the middle level through convective activities. The temperature increase, due to the effects estimated from the difference of $\theta_{e}^{*}$ profiles between Figs. $23 \mathrm{a}$ and $23 \mathrm{~b}$, has the vertical profile with almost the same characteristic features as that of apparent heating around the Baiu frontal zone (e.g., Hase and Niino 2005). The effects of 
(a)

(b)

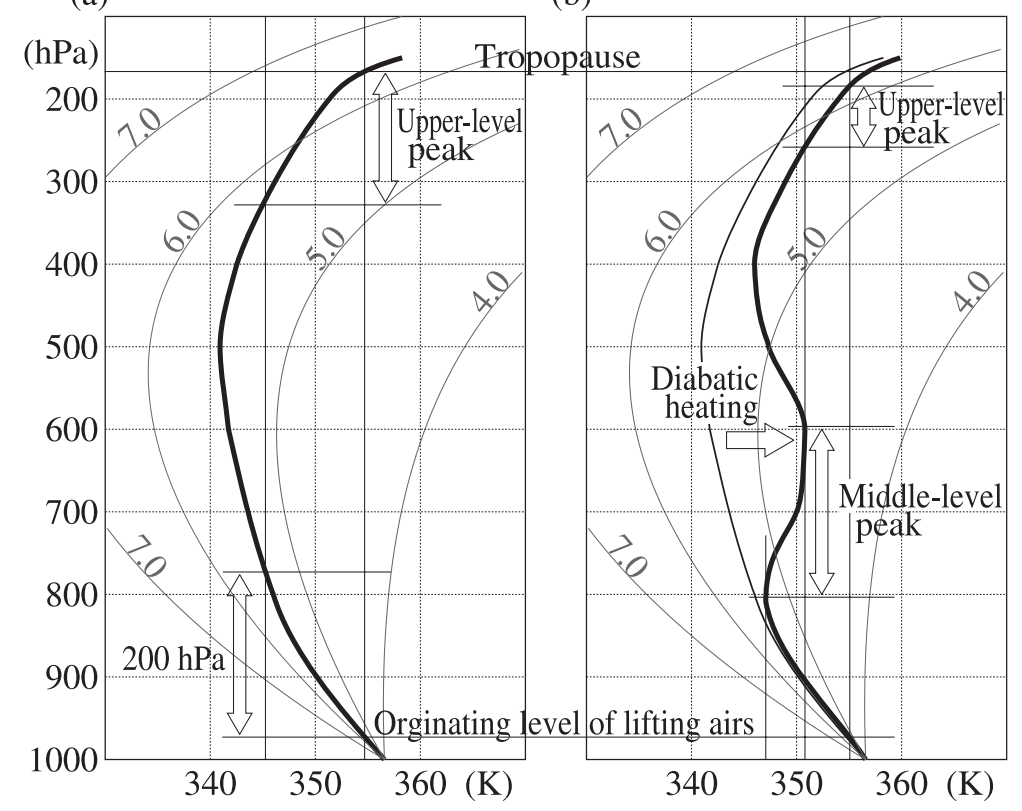

Fig. 23. Schematic diagram of the formation of the peaks in the appearance rate of the level of neutral buoyancy (LNB) around the Baiu frontal zone. (a) Cases in which the LNB appears only at an upper level around $150 \mathrm{hPa}$, and (b) it also appears at a middle level around $700 \mathrm{hPa}$. Temperature at a $1000 \mathrm{hPa}$-level is assumed $25^{\circ} \mathrm{C}$. Bold curves denote the typical vertical profile of the saturated equivalent potential temperature $\theta_{e}^{*}$, estimated from Figs. 10 and 11 . Originated level of a parcel is about 500-m altitude. Grey curves denote the vertical profiles of $\theta_{e}^{*}$ with constant lapse rates of $4,5,6$, and $7 \mathrm{~K} \mathrm{~km}^{-1}$. In (b), the typical vertical profile of $\theta_{e}^{*}$ in case of (a) is also shown by second bold curve.

diabatic heating could reduce the $\Gamma$ around the middle level, especially around the layer between $600 \mathrm{hPa}$ and $700 \mathrm{hPa}$, and consequently the LNB is often estimated at the MP. Even for the vertical profile of $\theta_{e}^{*}$ shown in Fig. 23b, however, the LNB is estimated at the UP in case that the $\theta_{\text {emax }}$ of lifting airs is very high. Therefore, as shown in Fig. 23, the LNB around the Japan Islands strongly depends on the $\Gamma$ below the middle level in case that the $\theta_{e \max }$ of lifting airs is not very high. The threshold of the $\Gamma$ below the middle level to divide the UP and MP is about $5 \mathrm{~K} \mathrm{~km}^{-1}$.

The relatively stable atmospheric condition around the Japan Islands, found when the LNB appears at the MP, is mainly caused by the advection of a middle-level air that is warmed through convective activities over upstream regions, especially the China Continent. Such condition is also found in the other areas around the Baiu frontal zone, and consequently the LNB also frequently appears at the MP.
However the MP is not found over the western part of the North Pacific Ocean where a warmed air is not transported. Therefore, the MP found in the vertical profiles of the appearance rate of the LNB is one of the characteristic features around the Baiu frontal zone.

In the statistical study with radar data over the China Continent during the Baiu season, Zhang et al. (2006) found many cumulonimbi that formed under the surrounding atmospheric condition with the LNB that was calculated at the MP, in addition to deep convection. They defined such cumulonimbi as the convection of medium depth (CMD), and they showed that the CMD was more predominant around the Baiu frontal zone than the deep convection.

Johnson et al. (1999) pointed out that some cumulonimbi over the Pacific Ocean were suppressed to develop, due to a small $\Gamma$ at the middle level that was caused by adiabatic heating associated with downdrafts from deep convection, and consequently the convection whose 
cloud top existed at the middle-level formed, such as the CMD. They called such convection cumulus congestus. The $\Gamma$ over the Pacific Ocean exceeds $6 \mathrm{~K} \mathrm{~km}^{-1}$, which indicates the formation of deep convection (see Fig. A2). Therefore downdrafts from deep convection have to cause a large decrease of the $\theta_{e}^{*}$, $(>20 \mathrm{~K})$ at the middle level to generate the cumulus congestus. However since it is unrealistic, the evaporation effect of hydrometeors below the middle level is emphasized (e.g., Takayabu et al. 2006). On the other hand, the small $\Gamma$ below the middle level around the Baiu frontal zone is brought through latent heat release associated with convective activities, described above. Therefore the formation mechanisms of the convection whose cloud top exists at the middle level are completely different between the Baiu frontal zone and the $\mathrm{Pa}$ cific Ocean.

In this study, the relationship between the LNB and cloud top heights of cumulonimbi is roughly examined using observed positions of lightning, for heavy rainfall cases in June and July. The distribution of lightning indicates that many cumulonimbi in the case of June developed lower than those in the case of July. This agrees with the distribution of the LNB. Therefore the LNB is useful for the examination on the development of cumulonimbi. However since these results are obtained from two case studies, further comparisons with observations are necessary to clarify the relationship between the LNB and cloud top heights of cumulonimbi. These are our future issues.

The statistical results in this study show only the fundamental atmospheric conditions around the Baiu frontal zone, in the case that cumulonimbi can form and develop. This is because rainfall is observed with the appearance rate of about $10 \%$ in western Japan during the Baiu season (Kato 2005), while the appearance rate of the LNB is $0.2 \sim 0.4$ (Fig. 3). Moreover rainfall is also brought from stratiform clouds, in addition to cumulonimbi. Therefore the appearance rate of rainfall, which is observed when the LNB can be calculated, has to be statistically examined to clarify the availability for the use of the LNB. Moreover the MP that appears around $700 \mathrm{hPa}$ is considerably lower in comparison with the observations (e.g., Zhang et al. 2006). Cumulonimbi associated with the middle-level LNB maintain their upward motions above the LNB against the negative buoyancy that is considerably smaller than around the tropopause. This maintenance process can be examined using cloud-resolving models. Therefore further statistical analyses with observations and numerical simulations should be required to ascertain the relationship between the LNB and the cloud top heights of cumulonimbi, to clarify the examinations on the MP in this study. These are also our future issues.

\section{Acknowledgement}

The authors are grateful to Mr. H. Eito and their colleagues of the Meteorological Research Institute (MRI) for their constructive comments. They also thank Prof. Y. Takayabu of the University of Tokyo for her helpful comments. Thanks are extent to two anonymous reviewers for their constructive comments.

\section{Appendix}

\section{Dependency of the level of neutral buoyancy (LNB) on the low-level temperature and the lapse rate}

The vertical profiles of potential temperature $\theta$ and saturated potential temperature $\theta_{e}^{*}$ in the case with the temperature $T$ of $298.16 \mathrm{~K}$ $\left(25^{\circ} \mathrm{C}\right)$ at a level of $1000 \mathrm{hPa}$ and a constant lapse rate $\Gamma$ of $6 \mathrm{~K} \mathrm{~km}^{-1}$ are shown in Fig. A1. Since this $\Gamma$ is smaller than the dry adiabat lapse rate $\left(\sim 9.8 \mathrm{~K} \mathrm{~km}^{-1}\right)$, the atmospheric condition for a dry air is stable, i.e., the $\theta$ increases with height. On the other hand, the minimum $\theta_{e}^{*}$ of $334.1 \mathrm{~K}$ is found at a level of $532 \mathrm{hPa}$. Such a level of the minimum $\theta_{e}^{*}\left(L \theta_{e m i n}^{*}\right)$ is produced from the relationship between the enthalpy $C_{p} \theta\left(C_{p}\right.$ : the specific heat at constant pressure) and the maximum latent energy of water vapor that can be included in an air; the $C_{p} \theta$ increases with height, while the maximum latent energy of water vapor usually decreases with height.

The level of neutral buoyancy (LNB) is examined by lifting an air from a level of $1000 \mathrm{hPa}$, under the atmospheric condition shown in Fig. A1. In the case that the equivalent potential temperature $\theta_{e}$ of a lifted air is lower than $334.1 \mathrm{~K}$ (i.e., its relative humidity is lower than $62 \%$ ), the LNB is never calculated because 


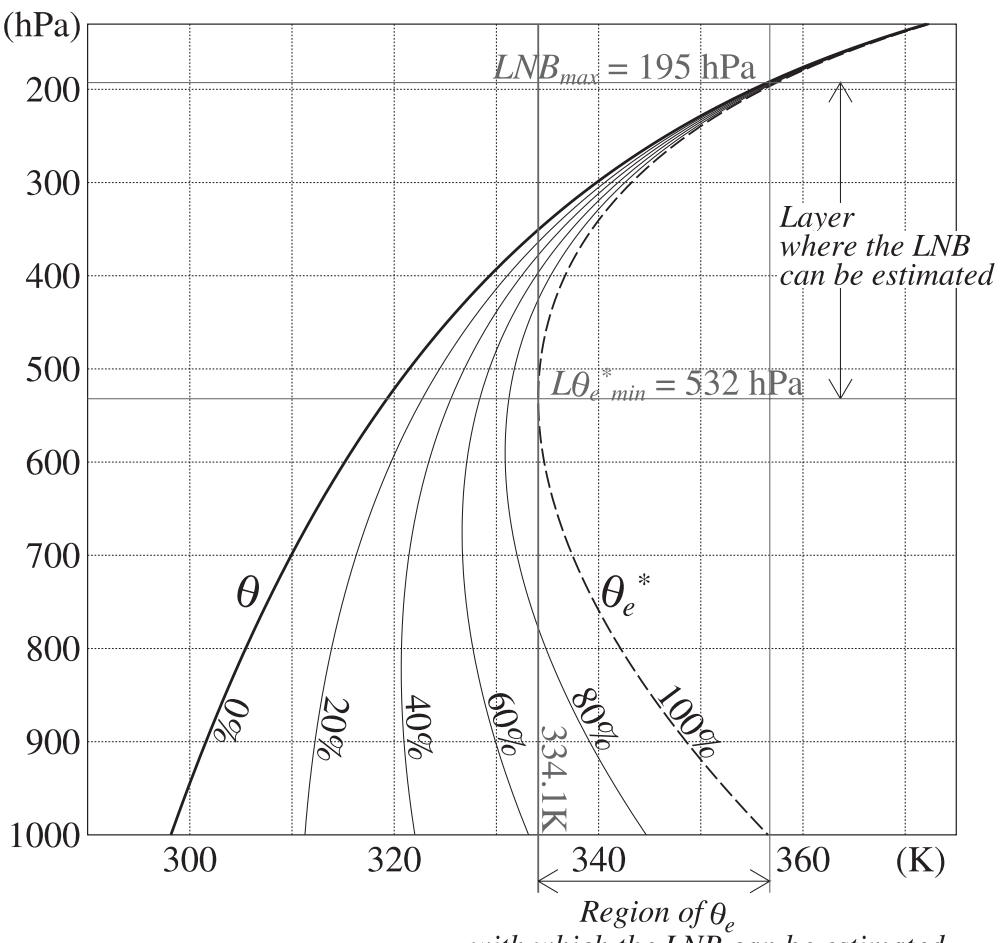

Fig. A1. Region of $\theta_{e}$ with which and layer where the $L N B$ can be estimated in the case with the temperature of $298.16 \mathrm{~K}\left(25^{\circ} \mathrm{C}\right)$ at a level of $1000 \mathrm{hPa}$ and the lapse rate of $6 \mathrm{~K} \mathrm{~km}^{-1}$. Bold and broken lines denote the profiles of potential temperature and saturated equivalent potential temperature $\theta_{e}^{*}$, respectively. Thin lines present the profiles of equivalent potential temperature with the relative humidity of $20,40,60$, and $80 \% . L N B_{\max }$ is the highest level of $L N B$, and $L \theta_{e m i n}^{*}$ is the level at which the minimum of $\theta_{e}^{*}$ is found.

the $\theta_{e}^{*}$ is higher than the $\theta_{e}$. On the contrary, in the case with the $\theta_{e}$ of a lifted air higher than $334.1 \mathrm{~K}$, the LNB can be calculated above the $L \theta_{e m i n}^{*}$, and it becomes highest for $\theta_{e}=\theta_{e}^{*}$ at a level of $1000 \mathrm{hPa}$. The highest $\mathrm{LNB}\left(\mathrm{LNB}_{\max }\right)$ in this case is $195 \mathrm{hPa}$. Therefore, the LNB is necessarily calculated between the $L \theta_{e m i n}^{*}$ and $\mathrm{LNB}_{\text {max }}$ in the case without another level of the minimum $\theta_{e}^{*}$, independently of the vertical $\theta_{e}^{*}$ profile below the $L \theta_{e m i n}^{*}$.

The dependency of the $L \theta_{e \min }^{*}$ and $\mathrm{LNB}_{\max }$ on the $\Gamma$ and low-level $T$ is examined. Figure A2a shows the vertical $\theta_{e}^{*}$ profiles in the case with the $1000 \mathrm{hPa}$-level $T$ of $298.16 \mathrm{~K}\left(25^{\circ} \mathrm{C}\right)$ and the $\Gamma$ of $4,5,6,7,8$ and $9 \mathrm{~K} \mathrm{~km}^{-1}$. The $L \theta_{\text {emin }}^{*}$ (symbolized by $\mathbf{x}$ in Fig. A2a) and $\mathrm{LNB}_{\text {max }}$ (symbolized by $\bigcirc$ ) become lower as the $\Gamma$ decreases. Figure A2b shows the dependency of the $\mathrm{LNB}_{\max }$ and $L \theta_{e \min }^{*}$ on the $\Gamma$ under atmospheric conditions with the $1000 \mathrm{hPa}$-level
$T$ of $298.16 \mathrm{~K}\left(25^{\circ} \mathrm{C}\right), 288.16 \mathrm{~K}\left(15^{\circ} \mathrm{C}\right)$ and $278.16 \mathrm{~K}\left(5^{\circ} \mathrm{C}\right)$. In the case of the $1000 \mathrm{hPa}$ level $T$ of $298.16 \mathrm{~K}$, the bold solid curve shown in Fig. A2b is drawn by setting the $\Gamma$ in an axis of abscissa and the $L \theta_{e \min }^{*}$ (symbolized by $\mathbf{X}$ in Fig. A2a) in an axis of ordinate. Similarly, the thin solid curve shown in Fig. A2b is drawn by setting the $\mathrm{LNB}_{\max }$ (symbolized by $\bigcirc$ ) in an axis of ordinate. In Fig. A2b, the LNB is necessarily found in the region between these two curves. For example, the LNB in the case with the $\Gamma$ of $6 \mathrm{~K} \mathrm{~km}^{-1}$ can be found between $532 \mathrm{hPa}$ and $195 \mathrm{hPa}$, as described above. The other cases for atmospheric conditions with the $1000 \mathrm{hPa}$-level $T$ of $288.16 \mathrm{~K}$ and $278.16 \mathrm{~K}$ are shown by the broken and dashed curves in Fig. A2b, respectively.

The dependency of the LNB on the low-level $T$ is examined for the case with the same $\Gamma$. Both the $\mathrm{LNB}_{\max }$ and $L \theta_{\text {emin }}^{*}$ become higher as 
(a)



(b)

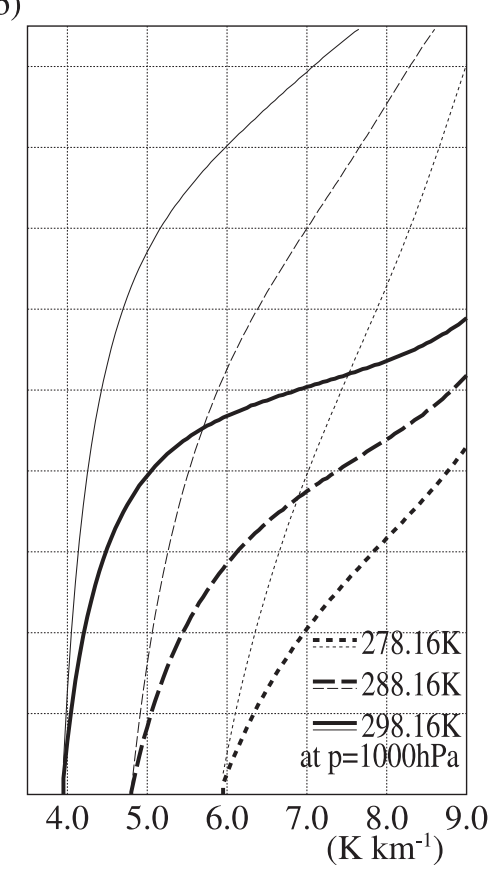

Fig. A2. (a) Profiles of saturated equivalent potential temperature $\theta_{e}^{*}$ in the case with the temperature of $298.16 \mathrm{~K}\left(25^{\circ} \mathrm{C}\right)$ at a level of $1000 \mathrm{hPa}$ and the lapse rate of $4,5,6,7,8$ and $9 \mathrm{~K} \mathrm{~km}^{-1}$. Cycles $(O)$ and crosses $(\mathbf{X})$ denote the highest LNB $\left(\mathrm{LNB}_{\max }\right)$ and the level with the minimum $\theta_{e}^{*}$ $\left(L \theta_{\text {emin }}^{*}\right)$, respectively. (b) $\mathrm{LNB}_{\max }$ (thin lines) and $L \theta_{\text {emin }}^{*}$ (bold lines) estimated from the atmospheric condition with the temperature of $298.16 \mathrm{~K}\left(25^{\circ} \mathrm{C}\right.$, solid line), $288.16 \mathrm{~K}\left(15^{\circ} \mathrm{C}\right.$, broken line) and $278.16 \mathrm{~K}\left(5^{\circ} \mathrm{C}\right.$, dashed line $)$ at a level of $1000 \mathrm{hPa}$ and the lapse rate that is shown by an axis of abscissa.

the $1000 \mathrm{hPa}$-level $T$ increases. For example, in the case with the $\Gamma$ of $6 \mathrm{~K} \mathrm{~km}^{-1}$, the $\mathrm{LNB}_{\text {max }}$ is $195 \mathrm{hPa}$ for the $1000 \mathrm{hPa}$-level $T$ of $298.16 \mathrm{~K}$, $470 \mathrm{hPa}$ for that of $288.16 \mathrm{~K}$ and $950 \mathrm{hPa}$ for that of $278.16 \mathrm{~K}$. It should be noted that the $\mathrm{LNB}_{\text {max }}$ changes continuously for the increase of low-level $T$. Therefore the LNB at the middle level $(\sim 700 \mathrm{hPa})$ never jumps to the upper level $(\sim 150 \mathrm{hPa})$ for the increase of low-level $T$. Further, the change of the $\mathrm{LNB}_{\max }$ is small for that of low-level $T$ observed around the Baiu frontal zone ( $\sim$ a few degrees). For example, the $\mathrm{LNB}_{\text {max }}$ becomes higher by about $100 \mathrm{hPa}$, when the low-level $T$ increases by $3 \mathrm{~K}$ from $297 \mathrm{~K}$ under the atmospheric condition with a constant $\Gamma$ of $5 \mathrm{~K} \mathrm{~km}^{-1}$.

Next, the dependency of the LNB on the $\Gamma$ is examined for the case with the same low-level $T$. Both the $\mathrm{LNB}_{\text {max }}$ and $L \theta_{\text {emin }}^{*}$ rapidly become lower as the $\Gamma$ decreases. In the case with $1000 \mathrm{hPa}$-level $T$ of $298.16 \mathrm{~K}$, the $\mathrm{LNB}_{\max }$ and
$L \theta_{\text {emin }}^{*}$ are respectively $603 \mathrm{hPa}$ and $330 \mathrm{hPa}$ for $\Gamma=5 \mathrm{~K} \mathrm{~km}^{-1}$, and they do not change so much for $\Gamma>5 \mathrm{~K} \mathrm{~km}^{-1}$. On the contrary, they rapidly become lower for $\Gamma<5 \mathrm{~K} \mathrm{~km}^{-1}$, and this lowering is more remarkable in the $\mathrm{LNB}_{\max }$. Therefore, the small $\Gamma$ not only causes the remarkable lowering of the LNB, but also it limits the region where the LNB can be estimated (i.e., the region between the $\mathrm{LNB}_{\max }$ and $L \theta_{\text {emin }}^{*}$ ).

Figure A2b also shows thresholds of the $\Gamma$ for the existence of the LNB (e.g., $3.9 \mathrm{~K} \mathrm{~km}^{-1}$ in the case with $1000 \mathrm{hPa}$-level $T$ of $298.16 \mathrm{~K}$ ). This $\Gamma$ completely corresponds to the moist adiabat lapse rate $\Gamma_{m}$, and it means that the LNB never exists under the absolutely stable condition with $\Gamma<\Gamma_{m}$ (i.e., for $d \theta_{e}^{*} / d z>0$ ).

\section{References}

Bolton, D., 1980: The computation of equivalent potential temperature. Mon. Wea. Rev., 108, 1046-1053. 
Hase, E. and H. Niino, 2005: Characteristic features of large-scale field during the 1999 Baiu season. Meteor. Res. Notes, 208, 37-51 (in Japanese).

Hirose, M. and K. Nakamura, 2005: Spatial and diurnal variation of precipitation systems over Asia observed by the TRMM Precipitation Radar. J. Geophys. Res., 110, D05106, doi:10.1029/2004JD004815.

Japan Meteorological Agency, 2002: Outline of the operational numerical weather prediction of the Japan Meteorological Agency. 158 pp. [Available from JMA, 1-3-4 Otemachi, Chiyoda-ku, Tokyo 100-8122, Japan.]

Johnson, R.H., T.M. Rickenbach, S.A. Rutledge, P.E. Ciesielski, and W.H. Schubert, 1999: Trimodal characteristics of tropical convection. J. Climate, 12, 2397-2418.

Kato, T., 1998: Numerical simulation of the bandshaped torrential rain observed over southern Kyushu, Japan on 1 August 1993. J. Meteor. Soc. Japan, 76, 97-128.

Kato, T., 1999: Verification of the MRInonhydrostatic-model predicted rainfall during the 1996 BAIU season. Part 2: Effects of icephase and atmospheric radiation. CAS/JSC WGNE Res. Activ. Atmos. Oceanic Modell., 28, 411-412.

Kato, T. and H. Goda, 2001: Formation and maintenance processes of a stationary band-shaped heavy rainfall observed in Niigata on 4 August 1998. J. Meteor. Soc. Japan, 79, 899924.

Kato, T., M. Yoshizaki, K. Bessho, T. Inoue, Y. Sato, and X-BAIU-01 observation group, 2003: Reason for the failure of the simulation of heavy rainfall during X-BAIU-01-Importance of a vertical profile of water vapor for numerical simulations-. J. Meteor. Soc. Japan, 81, 9931013.
Kato, T., 2005: Statistical study of band-shaped rainfall systems, the Koshikijima and Nagasaki lines, observed around Kyushu Island, Japan. J. Meteor. Soc. Japan, 83, 943-957.

Kato, T. and K. Aranami, 2005: Formation factors of 2004 Niigata-Fukushima and Fukui heavy rainfalls and problems in the predictions using a cloud-resolving model. SOLA, 1, 1-4.

Kato, T., 2006: Structure of the band-shaped precipitation system inducing the heavy rainfall observed over northern Kyushu, Japan on 29 June 1999. J. Meteor. Soc. Japan, 84, 129-153.

Kawai, Y. and H. Kawamura, 2005: Spatial and temporal variation of model-derived diurnal amplitude of sea surface temperature in the western Pacific ocean. J. Geophys. Res., 110, C08012, doi:10.1029/2004JC002652.

Kurihara, K. and T. Kato, 1997: Characteristics of diurnal variation of precipitation around Kyushu Distinct during the Baiu season. Tenki, 44, 631-636 (in Japanese).

Matusmoto, S., K. Ninomiya, and S. Yoshizumi, 1971: Characteristic feature of Baiu front associated with heavy rainfall. J. Meteor. Soc. Japan, 49, 267-281.

Takahashi, T., 1984: Thunderstorm electrificationA numerical study. J. Atmos. Sci., 41, 25412558.

Takayabu, Y.N., J. Yokomori, and K. Yoneyama, 2006: A diagnostic study on interactions between atmospheric thermodynamic structure and cumulus convection over the tropical Western Pacific Ocean and over the Indochina Peninsula. J. Meteor. Soc. Japan, 84A, 151169.

Zhang, C.-Z., H. Uyeda, H. Yamada, B. Geng, and Y. $\mathrm{Ni}, 2006$ : Characteristics of Mesoscale Convective Systems over the East Part of Continental China during the Meiyu from 2001 to 2003. J. Meteor. Soc. Japan, 84, 763-782. 